\title{
PHYLOGENETIC ANALYSIS AND FOSSIL PLANTS
}

\author{
WILLIAM E. STEIN, JR. \\ Museum of Paleontology, University of Michigan, Ann Arbor, MI 48109 (U.S.A.)
}

(Received January 13, 1986; revised and accepted August 19, 1986)

\begin{abstract}
Stein Jr., W.E., 1987. Phylogenetic analysis and fossil plants. Rev. Palaeobot. Palynol., 50: 31-61.

This paper presents a perspective on the relationship between cladistic methods and the study of fossil plants. Paleobotany has been slow in evaluating the potential of these and other explicit methods compared to other branches of systematics. However, the unique or particularly difficult problems paleobotanists face make more interesting, rather than prohibit, their application. A model of a cladistic approach to phylogenetic analysis is introduced in order to evaluate what role fossils, including fossil plants, should play in phylogenetic analysis. Major elements of the model include sets of hypotheses about useful systematic comparison, phylogenetic relationship, evolutionary pattern and process, and age, linked by recursive directional arguments. Arguments at one level only, those linking characters with the cladogram, are viewed as being strictly deductive. Character hypotheses at the highest level are distinguished by the term "cladistic character". When cladistic characters are compatible, estimates of phylogeny suggested by each may be readily combined into a summary result. However, character conflict is common and represents a major challenge to the ultimate success of cladistic methods. The main advantage of cladistic characters lies in the attempt to separate out portions of complex phylogenetic hypotheses for independent scrutiny and debate. Under the model of phylogenetic analysis presented here, it is argued that fossils provide morphological information, not obtainable by other means of inquiry, which may have a profound effect on our view of characters and relationship. Fossils also provide estimates of age useful in two distinct ways. The first involves using age estimates of states, combined with external criteria such as out-group analysis, in providing defensible proximity and polarity proposals for cladistic characters. The second involves using age estimates of entire taxa to judge historical plausibility of a set of phylogenetic hypotheses generated from a cladogram. Incompatible characters may also be analyzed in this way, allowing evaluation of the plausibility of alternative character formulations. The use of fossils in phylogenetic analysis tends to emphasize the necessity of coming to terms explicitly with the ancestor-descendant relationship in cladistic methods. It is proposed that, when properly formulated, the relationship is similar in structure to other phylogenetic hypotheses and at least partly addressed by the hypothetico-deductive format.
\end{abstract}

\section{Introduction}

My assignment in this symposium is to interpret the continuing debate about phylogenetic methods, especially cladistic methods, and to provide a perspective on how they relate to paleobotany. This, in itself, is a tall order. However, there is a larger and fundamentally more interesting question: just what role (within cladistic or other methods) should fossil evidence of any kind be allowed to play in the analysis of pattern and process in evolutionary systematics? This larger question invites us, as paleobotanists or systematic botanists, to adopt a comparative outlook toward the many sub-disciplines of systematics. In addition, it forces us to consider the philosophical basis of what we, and others, are trying to accomplish. Most of what follows will be addressed to phylogenetic aspects of this larger question. I will begin, however, by considering a portion of the more restricted problem. 


\section{New methods in paleobotany}

What effect have new phenetic and/or cladistic methods of systematics (see Felsenstein, 1982 for a general survey of different kinds), derived entirely from outside paleobotany in the past twenty or so years, had on our field? Certainly by now, one can point to their application in several contexts (Crane and Manchester, 1982; Doyle et al., 1982; Hill and Crane, 1982; Niklas and Gensel, 1982; Stein et al., 1984; Wing and Hickey, 1984; Crane, 1985; Doyle and Donoghue, 1986a). However, I would argue that their effect on the field overall has been minimal. Only a little theoretical discussion has been generated on the appropriateness of the applications (see above, and Smoot et al., 1981; Crane, 1984; DiMichele, 1985; Rothwell, 1985; Doyle and Donoghue, 1986b), and even this seems somewhat tentative compared to similar discussions in other fields of systematics. Most of paleobotany continues as if the new methods contain little of relevance, and this is despite the fact that some of the new methods (particularly cladistics) are claimed to provide significantly greater precision toward one of the major goals of paleobotanical inquiry - the determination of phylogenetically based, systematic relationship. Why has paleobotany been so reluctant to address, theoretically evaluate, and either employ or reject, these methods?

One reason, no doubt, stems from the unreasonable positions taken at times by both phenetic and cladistic methodologists on several issues, not the least of which is the supposed "unknowability" of past evolutionary patterns or events. Paleobotanists, accustomed to working with evidence of the past, are generally convinced of the evolutionary significance of the patterns they observe, and they are not likely to be dissuaded from this point of view by sweeping methodological statements. This is especially true in circumstances where the methodologists seem to display little firsthand knowledge of the data they propose to dismiss. These concerns, for the most part, are sociological as opposed to scientific, and by no means limited to paleobotany. It appears, however, that there are additional and, perhaps, more fundamental reasons for the skepticism felt by many paleobotanists. I will distinguish two concerns below by the convenient terms "The Paleobotanical Reason", and "The Botanical Reason". To some extent, I may overstate these propositions. Arguments along these lines are often heard, however, and it is my intent to suggest that they demand careful examination before being accepted as true limitations.

\section{The paleobotanical reason}

The problems of paleobotany are more difficult than are related problems in other fields, including those which have given rise to the new methods. Paleobotanical evidence is fragmentary and, because the overall habit of plants is very difficult to predict from isolated parts, paleobotanists are not very advanced in the development of reliable concepts of homology, or biologically interpretable "whole" taxa. Application of new phenetic or cladistic techniques, designed for study groups of "whole" organisms, may therefore imply a greater degree of precision than is warranted by the data, and is judged to be premature.

\section{The botanical reason}

Methods for analyzing systematic relationships derived from organisms other than plants, especially those suggested to us by our zoological colleagues studying higher vertebrates, often contain a parochial approach to underlying process assumptions. Because these assumptions often fail to treat certain aspects of plant development, genetics, population structure, or reproductive behavior in a realistic manner, the justification for applying these methods to plants, either living or extinct, is tenuous at best.

I have little doubt that both of these concerns are legitimate problems requiring serious consideration in the application of the new methods to paleobotany. Extinct plants are, indeed, some of the most difficult organisms to reconstruct. Paleobotanists must envy 
the vertebrate paleontologist, for example, when he regularly succeeds in drawing a larger range of biologically significant conclusions from equally disarticulated specimens. The latter's success is due primarily to a more clearly defined system of organs in his taxa, but in some cases he is also assisted by the strong sense that one organ (for instance, the dentition in mammals; Gingerich, 1974) can stand by itself, when necessary, in supporting biological concepts of "whole" taxa. By contrast, the study of extinct plants almost always requires more direct evidence of the different fossil parts in organic connection before reliable biological concepts begin to emerge. Thus, to a degree rarely observed elsewhere, considerable excitement is generated in paleobotany when isolated organs are linked, and heated debates ensue about whether particular reconstructions are, in fact, well-founded.

Despite these problems, however, progress in paleobotany has been, and continues to be made, and we should look forward to using this hard-won information in novel ways. Taxa from a wide range of major groups are well known, some perhaps as well or better than most living plants, and much might be gained by analyzing even the less completely known taxa with more precise methods. The cladistic methods presented here, for instance, do not presuppose that we know everything there is to know about any living or fossil plant, only that we attempt to view what evidence we have in biological terms. In doing so, we must always bear in mind the degree of confidence attained in the reconstruction of any particular taxon. In fact, the tension produced between precise arguments of phylogenetic relationship, and our estimates of confidence in individual taxa, helps us to see more clearly the logical consequences of many opinions we already hold. This can only be viewed as an advance in understanding.

Concerning the issue of underlying process in plants, there is little doubt that certain aspects of the biology of plants (indeterminate growth, polyploidy, hybridization, etc.) present particularly difficult problems largely un- addressed by zoologically derived models of biological processes. However, an accusation of parochialism cuts both ways. If the biological assumptions inherent in certain zoological methods are, in fact, incorrect or too simplistic for use in evolutionary botany, then it is part of the botanist's responsibility to point this out to the larger community of systematists, and to suggest modifications in the methods that, perhaps, will work for all organisms. Recent discussions of cladistic approaches to a possible reticulate geometry for phylogenetic patterns (as a result of hybridization), for instance (Humphries, 1983; Nelson, 1983; Wagner, 1983; Wanntorp, 1983), is a good example of what can be accomplished. If we fail to become involved in discussions of this sort, however, then everyone loses, but none more than ourselves.

What follows here is an attempt to join the discussion about phylogenetic methods from a paleobotanist's perspective. It consists of two parts. The first is a descriptive anatomy of phylogenetic analysis itself, argued from a cladistic perspective (see, for instance, Hennig, 1966; Wiley, 1981; and references cited below), emphasizing what I believe to be the dynamic and historical properties of the science. I maintain that this view is independent of the source of the empirical evidence, whether living or fossil, plant or otherwise. In the second part, I develop a general case for the unique and indispensable role that fossils play in phylogenetic analysis, drawing examples from paleobotany. In addition, I comment on problems involving fossils in general, or plant fossils in particular, that are often viewed as being especially troublesome. Because many of the issues discussed here are quite complex, what follows should not be interpreted as a new dogma, but rather, it is intended as a stimulus for further discussion.

\section{Phylogenetic analysis as a dynamic process}

Emphasis will be placed here on a model treating phylogenetic analysis as a dynamic 
historical process in its own right. This runs counter to more static notions, including the surprisingly common view, that in paleontological work it is necessary only to wait for the accumulation of new specimens before reasonably definitive statements about phylogenetic relationships may be derived. The latter approach seriously underestimates the important role hypotheses play in relation to an established framework of known "facts" and implies a stability to that framework which is clearly untenable. On the other hand, the so-called "irrationalist" perspective (Popper, 1970; Stove, 1982 referring specifically to Kuhn, 1970, and Feyerabend, 1975), asserting complete dependence of observation on theory, and the "incommensurability" of major theoretical systems, is equally static and, in my opinion at least, inappropriate. In phylogenetic analysis, as in most sciences, much of what we do might be termed "successive approximation" (Hull, 1967), but in the process of approximating, we are not trapped within the confines of our prior understanding. Instead, we break new ground.

\section{The model}

The major features of the model are presented in flowchart form in Fig.1. Each box represents a set of hypotheses (or even a more or less unified "theory" in some cases) with characteristics described, to some extent, below. Transitions between boxes represent the relationships between sets of hypotheses, often in the form of deductive or inductive arguments (see below), or a combination of the two. Directions of arrows suggests the major directions of arguments, that is, which set of hypotheses usually contain the premises, and which others the valid conclusions of arguments linking them. The several sets of hypotheses, indicated by the different boxes, are not necessarily equivalent in either level of generality or importance. In fact, generality and complexity appear to increase as one proceeds in any analysis. In most, if not all, cases it is relatively easy to conceive of valid reasons for replacing a single box in Fig.1, with

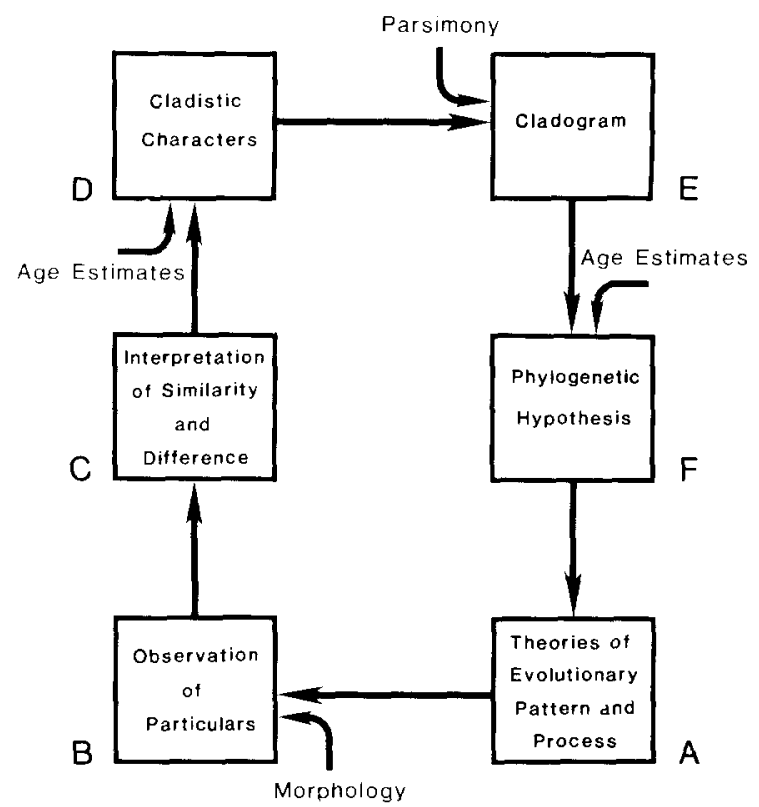

Fig.1. A model of phylogenetic analysis as a dynamic, historical, and recursive process. Boxes labelled $A-F$ represent sets of hypotheses. Arrows represent arguments linking sets of hypotheses. See text for further details.

several boxes (and intervening arrows) designed to represent certain aspects of phylogenetic analysis in more detail. Thus, what is presented here is only a summary of what, beyond doubt, is a very complex process involving hypotheses and arguments at several levels (Eldredge, 1979; Fisher, 1981).

Theories of evolutionary pattern and process (A)

By this, I mean previous hypotheses of phylogenetic relationship plus any associated theories of evolutionary process or mechanism which might have an impact on further phylogenetic observations or arguments. This box represents, in part, not only the "phylogenetic scenario" of Eldredge (1979), but also the sum total of "prior assessments" or "weight of tradition" that we always bring explicitly or implicitly into any "new" phylogenetic analysis.

"Observation" of particulars (B)

This and the next two boxes emphasize the complex and very important role characters 
play in phylogenetic analysis. At least three levels of hypothesis-making are involved. At the most basic level indicated here, the hypothetical nature of "observation", itself, is emphasized. This view acknowledges a partial theory dependence for "new" observations (Hull, 1980; Fisher, 1981), as well as a leveldependence in the concepts of pattern and process as we use them in phylogenetic analysis (Fisher, 1982).

\section{Interpretations of similarity and difference $(\mathrm{C})$}

Most estimates of phylogenetic relationship are based on assessments of shared similarity (i.e., fundamentally "the same", or "homologous" features) and, within that, observed differences in these same features. Most systematists are well aware of the practical difficulties involved in making these assessments and, I believe, the hypothetical nature of the "conclusions" we draw at this level.

\section{Cladistic characters (D)}

Hypotheses at this level, described in more detail below, involve a collection of specific statements about homology, some (but not all) similarities and differences, and relationship, based on "unitary" features of morphology observed in a study group.

\section{Cladogram (E)}

In this model, the cladogram is a limited hypothesis of character evolution and phylogenetic relationship for taxa in a study group. It is approximately equivalent to the "phylogenetic tree" level of Eldredge (1979), but may be somewhat less explicit regarding the historical context of taxa (see below). The cladogram is constructed by combining two or more cladistic characters using a well-defined argument of combination which preserves their original meaning. I suggest below that the combining of characters is best viewed as an entirely deductive process based on the characters alone. In most cladistic studies, however, accessory criteria are also employed, usually motivated by the general goal of keeping explanations of conflicting evidence as simple as possible (e.g., "parsimony", Sober, 1983; and below). The concept of the cladogram and its construction presented here contrasts sharply with the more common view (e.g., Eldredge, 1979 ) that a cladogram should be considered a more limited hypothesis of systematic relationship unable to distinguish sister groups from hypotheses of ancestry and descent. It also differs from the view of Beatty and Fink (1979) and Fisher (1981) who suggest that in addition to being limited as Eldredge suggests, a cladogram is a hypothesis independent of character evidence, judged to be consistent with the characters only to a greater or lesser extent.

\section{Phylogenetic hypothesis (F)}

This box represents a set of hypotheses generally at the same level, but usually in a more specific sense, than those termed "phylogenetic tree" by Eldredge (1979). This set contains not only hypotheses derived ultimately from the cladistic characters (including hypotheses of ancestry and descent), but also, estimates of age and any other form of evidence which may further define the topology of a tree or allow for interpretation of a phylogenetic pattern in a specific historical context.

\section{Recursion}

Perhaps the most important point to make about the model in Fig.1 is its overall recursive structure. By this, I mean that concepts in the field evolve through time in ways that are analogous to what in mathematics and computer science are termed recursive definitions or recursive functions (see Rogers, 1967; Yasuhara, 1971; Cutland, 1980; Péter, 1981; McNaughton, 1982, for technical definitions and some important distinctions between concepts; for an example of recursion applied to scientific inference, see Platt, 1964). The critical idea I wish to focus on here is the ability of a recursion to define particular steps in a process in terms of prior versions of themselves.

A familiar example of a recursion is the method used to generate the Fibonacci and 
related series of positive integers (Fig.2). Given prior definition of the values of the first two elements in the series $\left(X_{1}\right.$ and $\left.X_{2}\right)$, the value of the next member of the series $\left(X_{3}\right)$ is simply determined by adding the preceding two. Values of additional elements $\left(X_{n}\right)$ are obtained in sequence by incrementing $n$, and adding previously determined values $X_{n-1}$ and $X_{n-2}$. Note that there are two essential elements in this process: (1) the initial conditions (initial values for $n, X_{1}$, and $X_{2}$ ), and (2) a repetitive building function whose range, in this case, is infinite. In many instances, complex recursive functions, expressed in words, are mistaken for circular reasoning, either in the sense of begging the question (petitio principii), or being a form of circularity involving infinite regress (Hofstadter, 1980). However, it is important to realize the essential difference. Recursive functions are always based on the initial conditions (the so-called "initial step" of Burks, 1977) from which the values of all elements are ultimately derived. In addition, recursive functions, even if infinite, "progress" in the sense that they succeed in serially determining new values of a function in contrast with the "regress" of circular reason-

$$
\begin{aligned}
& \mathrm{n}=1,2,3,4,5,6, \quad 7, \quad 8, \quad 9, \quad 10, \ldots \\
& x=1,1,2,3,5,8,13,21,34,55, \ldots
\end{aligned}
$$
A

B

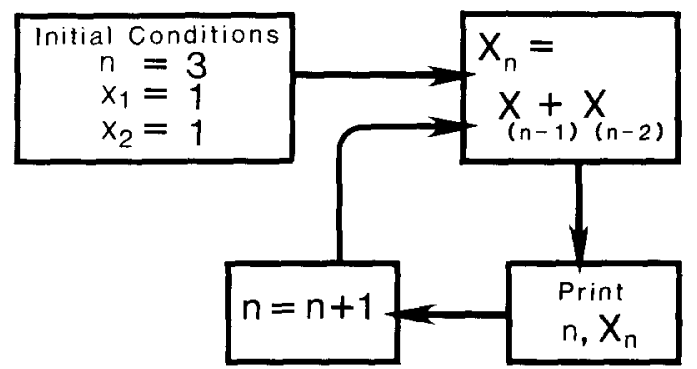

Fig.2. An example of recursion in generating the Fibonacci series of positive integers. A. List of the first few elements of the series, where $n$ represents the ordinal place for each element in the series, and $X$ represents the value of each element at place $n$. B. Simple flowchart for recursive generation of the series for $n>2$. ing where the activity vanishes, task with task, producing no result at all.

In proposing a recursive structure for phylogenetic analysis, I think we can go a long way toward developing a satisfactory explanation for the important role prior assessments play in the science. This explanation is viable not only within single phylogenetic analyses, but also for how the science as a whole has progressed at least since the introduction of evolutionary theory as a fundamental aspect of the problem. With recursion, phylogeneticists can successfully defend themselves against what has been a common criticism (e.g., Sokal and Sneath, 1963; Jensen, 1983), that use of past phylogenetic assessments as part of the process of making new ones is necessarily circular (see Hull, 1967). Also, with recursion, phylogeneticists need not satisfy the requirement (Nelson and Platnick, 1981; Brady, 1985) that arguments of pattern and process must necessarily be separate in some absolute way (see Fisher, 1982). Specific arguments about relationships often contain process assumptions (Hull, 1980; Beatty, 1982; Sober, 1983), and even embedded prior assessments of relationship, as for example, in "outgroup analysis" (e.g., Watrous and Wheeler, 1981; Donoghue and Cantino, 1984; Maddison et al., 1984). In complex circumstances like these, some arguments may very well be circular, but not all of them are necessarily so. Thus, within single analyses it becomes essential that one examine for circularity as many arguments as possible, case by case.

In a process as complex and multifaceted as phylogenetic analysis, recursion inevitably occurs not just once overall, but at several places and different levels in analysis. "Initial steps" occur wherever empirical evidence (however defined), or additional limiting assumptions, are allowed to enter into our assessments. Within the scheme of Fig.1, recursions are almost certainly a major component of most transitions, especially those which may be at least partly "inductive" in mode (see below). This complex arrangement, involving multiple input (and even modification of previous initial conditions), is compelling because it accurately 
describes the science. Rather than being strictly mechanistic as is, for example, the simple recursion of the Fibonacci series, complex recursions in phylogenetic analysis, involving a wide range of pattern and process hypotheses, seem to allow a degree of unpredictability, growth and, hopefully to some extent, selfcorrection (Hofstadter, 1980; Poundstone, 1985).

The next section addresses another aspect of what the arrows between the boxes in Fig.1 might be supposed to mean.

\section{Deduction versus induction}

Much has been written over the past decade about the preferred logical form of systematic inference (including both phylogenetic analy. sis and classification), related to similar questions in the philosophy of science, especially the relative merits of "deductive" versus "inductive" modes of argument (see, for instance, Bock, 1974; Harper, 1976, 1979; Kitts, 1977; Harper and Platnick, 1978; Nelson, 1978; Platnick and Gaffney, 1978a, b; Gaffney, 1979; Gingerich, 1979; Cartmill, 1981; Beatty, 1982; Brady, 1983, 1985; Farris, 1983; Hull, 1983; Sober, 1983). Deduction may be defined as the mode of argument where the conclusion follows directly from the premise by the rules of formal logic. It is important to note that the process termed "mathematical induction" (e.g., Jeffrey, 1981, p.52) falls within this definition. Induction, on the other hand, may be viewed as the case where the conclusion is related to, but not directly entailed, or determined, by the premise (Salmon, 1967; Kyburg, 1970; Copi, 1978).

The distinction between these two modes of argument, and the related distinction between "analytic" and "synthetic" statements respectively (Kant, 1787, p.48), is a basic and longstanding theme in the philosophy of knowledge and science (Kolenda, 1974; Suppe, 1977; Gould, 1985). Since Hume (1748), much debate has centered on the so-called "problem of induction" (Von Wright, 1957; Salmon, 1967; Popper, 1968), that is, determining whether or not induction is defensible as a means of gaining knowledge about the real world. As one might expect (given, for instance, that the meaning of every word in the previous sentence must be agreed upon first), arguments both pro and con are complex, and it would go beyond the scope of this paper (and competence of the author) to summarize even the major viewpoints here. It will suffice to note that some philosophers maintain that a reasonable defense of inductive arguments can be made a posteriori (dependent on confirmation by evidence) by resorting to an argument of probability (Kyburg, 1970; Burks, 1977). Others, notably Popper, reject the probability argument $(1968$, p.254) and, while not denying the existence of synthesis, nevertheless view induction as indefensible (part of the "psychology" as opposed to the "logic" of science, 1968, pp.30-32).

In phylogenetic analysis, the followers of Popper or other "falsificationists" (e.g., Lakatos, 1978), and others who, with varying explicitness, encourage use of the so-called "hypothetico-deductive method" (Braithwaite, 1955; Platt, 1964; Salmon, 1967; Gaffney, 1979) have, naturally enough, emphasized deductive arguments in attempts to provide a more "rigorous" or "logical" approach to the science. In my opinion, these attempts have had a beneficial effect for two major reasons. First, the "creative" or "conjectural" aspects of hypothesis formation have been given clear and unequivocal acknowledgement, freeing us from the constraint of having to propose theories that are somehow "definitively", even if inductively, derived. In fact, the falsificationists encourage daring in hypothesis-making, the goal being to come up with "improbable" or "bold" explanations of our observations which, in some sense, might be more easily overturned by critical tests. Second, emphasis has been placed on the importance of spelling out clearly, and in advance, at least some of the logical (deductive) consequences of the theories we propose. This process is necessary not only to specify the "basic statements" required for testing (Popper, 1968), but also to assist us in identifying potential logical problems in theories (tautologies or logical conflict) that may be legitimately criticized, but are unrelated to empirical evidence. 
Although the "hypothetico-deductive method" with its emphasis on deduction has much to offer phylogenetic analysis, it has become increasingly clear, for both philosophical and practical reasons, that the Popperian approach should not be carried too far (Kitts, 1977; Hull, 1983). For one thing (Salmon, 1967; Cartmill, 1981), it appears in reality that evaluation of phylogenetic hypotheses is not the strictly deductive modus tollens exercise it was once conceived to be. Although single instances of "falsification" (failure to observe a predicted outcome) may overturn extremely simple hypotheses in some cases, this rarely, if ever, happens for more complex hypotheses. Several philosophers of science have commented on the problem of theory choice in a wide variety of contexts (Kuhn, 1970; Lakatos and Musgrave, 1970; Schaffner, 1970; Laudan, 1977), but just how decisions should be made to "logically" accept or reject most hypotheses within the "hypotheticodeductive method" remains an open question.

A related problem is the failure of the Popperian scheme to actually live up to its credo: the elimination of all inductive arguments from the "logic" of science (Salmon, 1967; Newton-Smith, 1981). The fact that a potentially infinite number of hypotheses might be generated to cover a given set of observations, presents one challenge. How do we choose only the "reasonably good" ones to test? Even a cursory look at hypothesis generation in the actual practice of science shows far from a systematic search for, or an exhaustive set of, meaningful alternatives. Out of necessity, hypotheses are usually, if not always, developed associated with an implicit, or commonly, very explicit inductive rationale. This appears to be the only way to accomplishing any but the most trivial of scientific tasks.

As a practical matter, one lesson I draw from all of this is that although we should continue to reach beyond the evidence, and even logic, in seeking "bold" hypotheses for evaluation and testing, nevertheless, there is a limit (perhaps a probabilistic limit) on how far it is legitimate to go. This limit is probably closely related to our general goal of keeping explana- tion in science as simple as possible (Sober, 1975, 1983). At least in the historical sciences, there seems to be a key relationship between the development of a "good" new theory, and what we may view as a central "core" of evidence supporting it (e.g., Lakatos, 1978). New theories are judged not only on potential testability, but also by whether or not, in view of our goal to simplify whenever possible, it seems at all necessary to single out particular evidence for special explanation. Such considerations are not easily entertained within a strict "hypothetico-deductive method".

In the model of phylogenetic analysis presented in Fig.1, I suggest that both deduction and induction probably play important roles. Since many of the transitions indicated by arrows in Fig.1 $(B \rightarrow C, F \rightarrow A$, and even $A \rightarrow B)$ indicate arguments that seem to build ever more complex and unpredictable sets of hypotheses, it seems reasonable to view them as being at least partly inductive. One transition, however, that between the cladistic characters and the cladogram (Fig.1, $D \rightarrow E$ ), I argue, is best considered a strictly deductive argument. In the view developed in this paper, cladistic characters are full-fledged, though somewhat limited, phylogenetic estimates in their own right (see below). The cladogram is an attempt to combine the individual estimates into a single rational view. Thus, a statement linking cladistic characters to the cladogram is viewed as strictly analytic: the conclusion (cladogram) is entailed by the particular set of premises (cladistic characters) employed.

\section{Characters as hypotheses}

Fundamental to the phylogenetic model of Fig. 1 is the assertion that characters in phylogenetic analysis are hypotheses and estimates of phylogenetic relationship [limited "phylogenetic trees" (e.g., Eldredge, 1979)] as opposed to collections of observations, or "data", per se. From the cladistic perspective presented here, characters are formal, explicit, and highly structured. Following terminology suggested by Estabrook (1978), I distinguish a coherent set 
of character hypotheses at the highest level by the term "cladistic character" (see also, Meacham, 1980), and invite consideration here of its structure.

First, and of great importance, each cladistic character must be associated with an explicit statement about the limits of the set of organisms being evaluated. I call this set the "study group" (Fig.3, A and B). Upon occasion, I think, we tend to forget just how important a formal statement of this kind actually is. Examples abound in the literature where proposed characters are ambiguous in this regard and, as a result, we are left to wonder whether particular evolutionary hypotheses cover single groups, or whether they are intended to be more general, possibly covering all plant or animal taxa. Moreover, the problem is often compounded by imprecision in whether the characters are intended to be viewed as hypotheses of absolute "truth" over the proposed domain of taxa or whether they are meant to be "statistical" statements, true for members of the study group "often" or "sometimes" but not always.

Second, each cladistic character should be defined not only by the study group, but also by some unitary, "fundamental" or "homologous" aspect of morphology observed in members of the study group. In so far as possible, each character should be functionally and logically independent of other characters. Due to the fact that organisms are living functional units, and that characters are, in part, recursively defined, independence in actuality is rarely, if ever, achieved. However, we have at least some control over the degree of dependence.

Within the defined membership and morphological limits of the cladistic character, again following Estabrook (1983), it is useful to conceive of additional structure to cladistic characters. Three major structural elements may be recognized within a well-ordered hierarchy of dependence.

\section{State}

The most independent concept is termed "state". A state may be defined as a subgroup of taxa in the study group based on the observation that they share a specific and clearly defined feature or condition. It is hypothesized that the shared condition is evidence of a proximate common ancestor for the subgroup and, thus, as evidence of the subgroup's monophyletic or paraphyletic status [i.e., the state is "convex" (Estabrook, 1978)]. As in all cladistic methods, if one has reason to believe that the hypothesis of a proximate common ancestor is false for a particular state (i.e., the state is polyphyletic), then the state or character must be modified or discarded. Useful cladistic characters usually contain two or more alternative states which exclusively subdivide the character (Fig.3, C).

\section{Proximity}

"Proximity" is the structural element of a cladistic character describing a relationship between the states. The relationship is undirected, but represents hypotheses of evolutionary change leading to the common ancestor of each state within the study group. The concern at this level is how, in fact, states should be ordered, that is, which states share closer relationships to others (Fig.3, D). It should be clear that hypotheses of proximity depend on a prior assessment of states.

\section{Polarity}

The third structural element of a cladistic character, "polarity", is the proposed direction of the transitions between all pairs of most proximally related states (Fig.3, E). As such, polarity is clearly dependent on prior assessments of both proximity and states, but that is not all. Even within a particular arrangement of proximity and states, some polarity assessments are not allowed in most, if not all, cladistic methods (Fig.3, F). I interpret this as one of the many places where we allow our views of evolutionary pattern or process to constrain the structure of cladistic characters and, as a result, place a limit on the phylogenies that might be derived from them. 


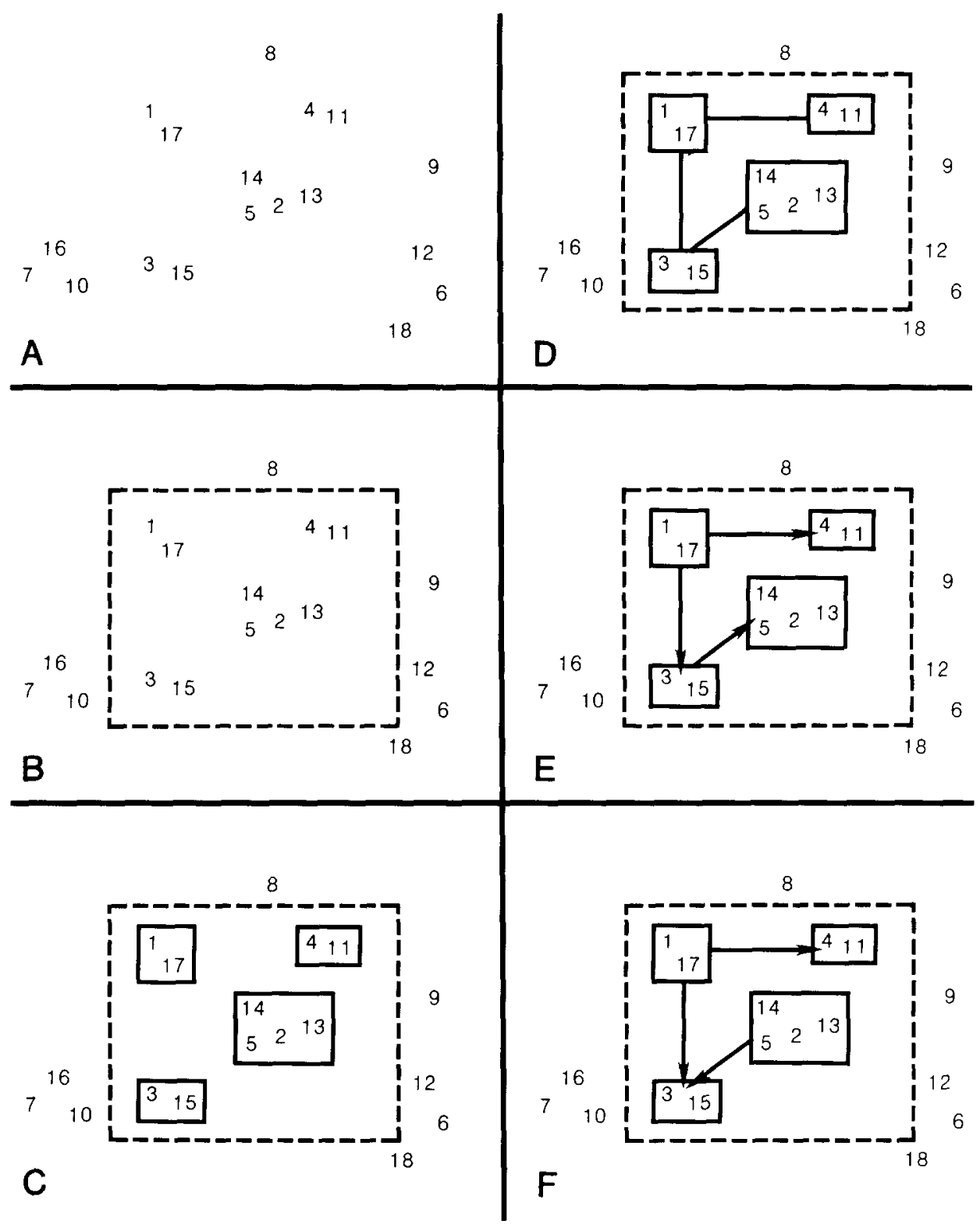

Fig.3. Structural elements of a cladistic character. See text for details. A. Taxa, indicated by numerals $1-18$, with overall morphologies summarized by the two dimensions of the plane of the paper. B. Dashed box encloses a "study group" for the cladistic character. C. Proposal of four "states" within the cladistic character (solid boxes), suggesting groupings: $\{1,17\},\{4$, $11\},\{3,15\}$, and $\{2,5,13,14\}$. D. Proposal of a "proximity" relationship linking the four states in C. E. Proposal of "polarity" for the combined state and proximity relationship in D. F. Proposal of polarity for this cladistic character usually not encountered in cladistic analysis. State $\{3,15\}$ is derived from a pair of ancestral states: $\{1,17\}$ and $\{2,5,13,14\}$. Hybrid or symbiotic origin of a taxon are models that might allow for a reasonable biological interpretation of this character structure. 


\section{Use of cladistic characters}

When cladistic characters are compatible, that is, when they are able to support at least one common phylogenetic hypothesis (Meacham, 1980), it is a simple matter to combine them into a more detailed view of phylogenetic relationship (Fig.4). If this were a world in which few mistakes were made in the construction of cladistic characters, addition of this kind would be all there is to at least the morphological aspects of phylogenetic analysis (e.g., Hennig, 1966). However, cladistic characters, especially those with enough complexity to be interesting, often conflict, and how to proceed under these circumstances is a major unresolved problem in cladistic methods, called "Hennig's dilemma" by Felsenstein (1982).

Hennig, himself, advised that, when encountering such problems, we should go back and restudy the characters (1966, p.121). By virtue of being considered for phylogenetic analysis in the first place, however, it may be argued that cladistic characters already rank among the best studied and, presumably, most errorfree available to us. The remaining mistakes, therefore, may be extremely subtle. For instance, parallelisms or reversals in DNA nucleotide sequences translated into proteins with exactly the same amino acid sequence, may be very difficult to detect, and it is possible to conceive of instances (such as parallel changes in single DNA base pairs) where we may never be able to locate and correct mistakes in our characters no matter how much additional study of morphology we undertake.

Another suggestion, also made by Hennig, is that we should seek instead (or in addition) other characters. This is motivated by the belief (or inductive argument based on past systematic experience) that a larger total number of characters is likely to increase our chances of deciding upon the "true" (historically correct) phylogeny (Felsenstein, 1982).

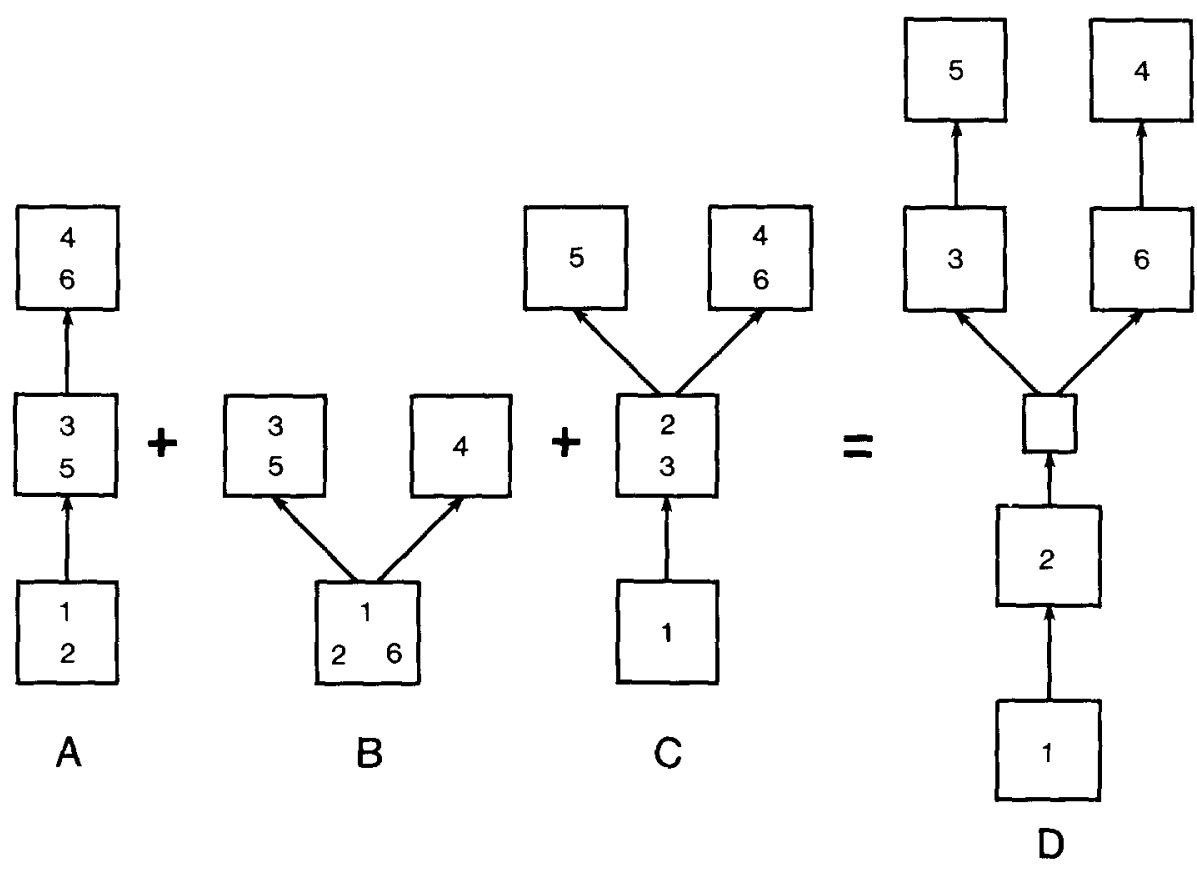

Fig.4. Combining three compatible cladistic characters $(A, B, C)$ for taxa $1-6$, into a cladogram $(D)$. Boxes represent states of the study group for each character. Each transition in the cladistic characters corresponds to one, and only one, transition in the cladogram. Grouping $\{3,4,5,6\}$, suggested by character $A$, combined with partitions of this set $\{3,5\}$ and $\{4,6\}$, suggested by characters $B$ and $C$, necessitates proposal of an "empty" state in the cladogram. 
However, supplementing our "best" characters, often the result of a long tradition of study, with new ones usually less well studied, is unlikely to give us confidence that we are, in fact, converging on the truth. In addition, simply collecting characters does nothing about resolving the conflict between characters that motivated the search in the first place.

There are no easy ways out of Hennig's dilemma. In many fields of systematics, it is possible to accumulate well-studied and useful supplemental characters, but where evidence is fragmentary (as in fossils) this may happen only at a slow rate. In the meantime, we are faced with little alternative but to follow Hennig's advice to restudy the characters, or resort to more clearly ad hoc measures (see below).

One of the main advantages of structuring morphology into cladistic characters lies in the attempt to follow Hennig's first suggestion. Making estimates of states, proximity, and polarity for each cladistic character force us to separate out portions of a very complex assemblage of hypotheses on morphology and evolution for independent scrutiny and debate. We may be able, as a result, to attain a level of precision in at least some areas of our analysis that is simply not possible overall. Although we may learn much from structuring cladistic characters in isolation, as much or more is gained by a careful analysis of the interaction
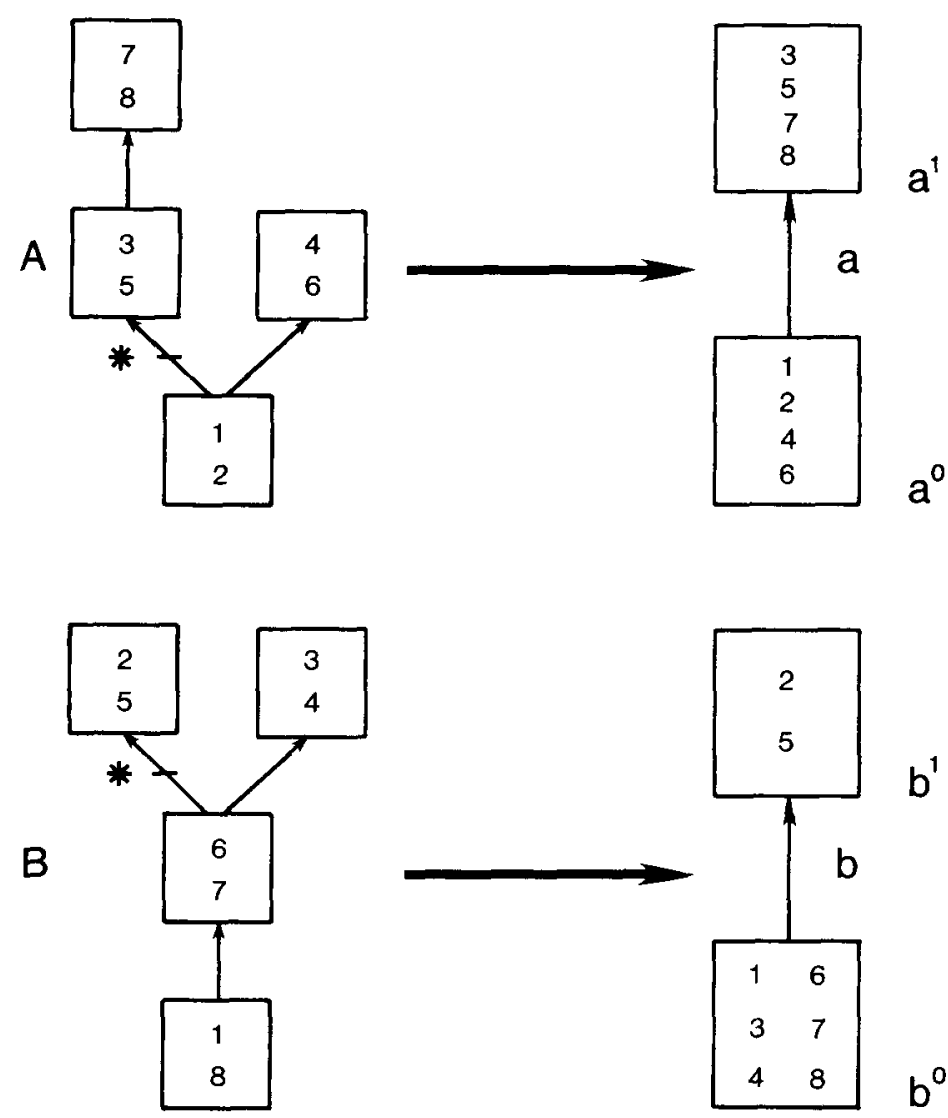

Fig.5. Examples of reduction of two cladistic characters ( $A$ and $B$ ) into 2-state structures $(a$ and $b$ ) for the purpose of analyzing compatibility. Asterisks indicate the transitions in $A$ and $B$ being considered. Derived states in the simplified characters are labelled $a^{\prime}$ and $b^{\prime}$, corresponding primitive states $a^{\circ}$ and $b^{\circ}$. 
between proposed character structure and the nature of the conflict itself. I shall develop this idea a little further here.

Complex cladistic characters, in fact, conflict in several different ways. In order to visualize the exact nature of the conflict, it is convenient to employ a graphical device (Figs.5-8) that allows for pairwise comparison of individual transitions of one character with similar transitions of another character (Estabrook et al., 1976; Meacham, 1980; Stein et al., 1984). This is done by reducing each cladistic character into a simple two-state structure, ignoring all but one transition in each character (Fig.5). Pairwise comparison of these simplified characters allows one to categorize each taxon in the study group (or intersection of study groups if the cladistic characters differ in this respect) in one of four possible ways (Fig.6). If all possibilities are represented in the study group [i.e., the graph forms a "cycle" (Stein et al., 1984)], then the characters conflict, and we know as a fact that at least one of the simplified characters, as an estimate of phylogeny at the level being evaluated, is in error (Wilson, 1965; LeQuesne, 1969; Meacham, 1980). Similar comparisons between other tran-

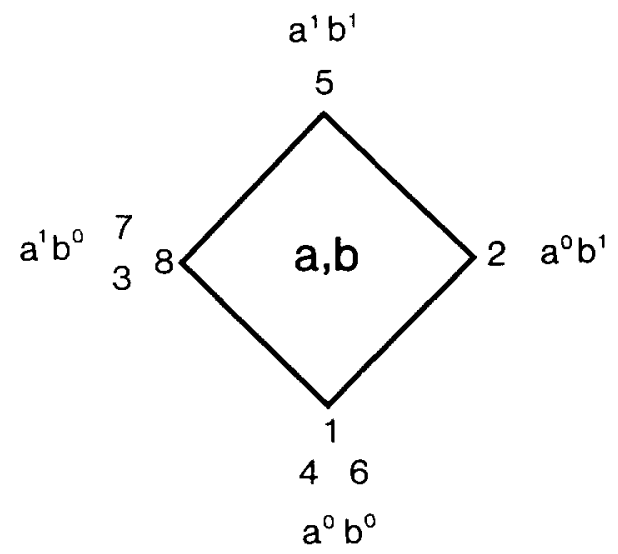

Fig.6. Incompatibility between simplified cladistic characters in Fig.5 represented in "cycle" form. Taxon 5 is found in the derived state of both simplified characters $\left(a^{\prime}, b^{\prime}\right)$; taxa $3,7,8$ are in the derived state of $a$ but primitive state of $b\left(a^{\prime}, b^{\circ}\right)$; taxon 2 is in the derived state of $b$ but primitive state of $a\left(a^{\circ}, b^{\prime}\right)$; taxa $1,4,6$ are in the primitive state for both $a$ and $b\left(a^{\circ}, b^{\circ}\right)$.

sitions in the pair of cladistic characters yield a complete picture of the overall pairwise conflict (Fig.7). Using the "pairwise compatibility theorem" (Felsenstein, 1982), all conflict in a set of cladistic characters is uniquely specified in this manner.

As a means of evaluating cladistic characters, it is instructive to try to visualize the pairwise conflict, observed as a combination of individual cycles, in terms of what changes in character structure might be sufficient to resolve it (Stein et al., 1984; Fig.8). Since characters are hypothetical constructs involving a complex arrangement of induction from

A
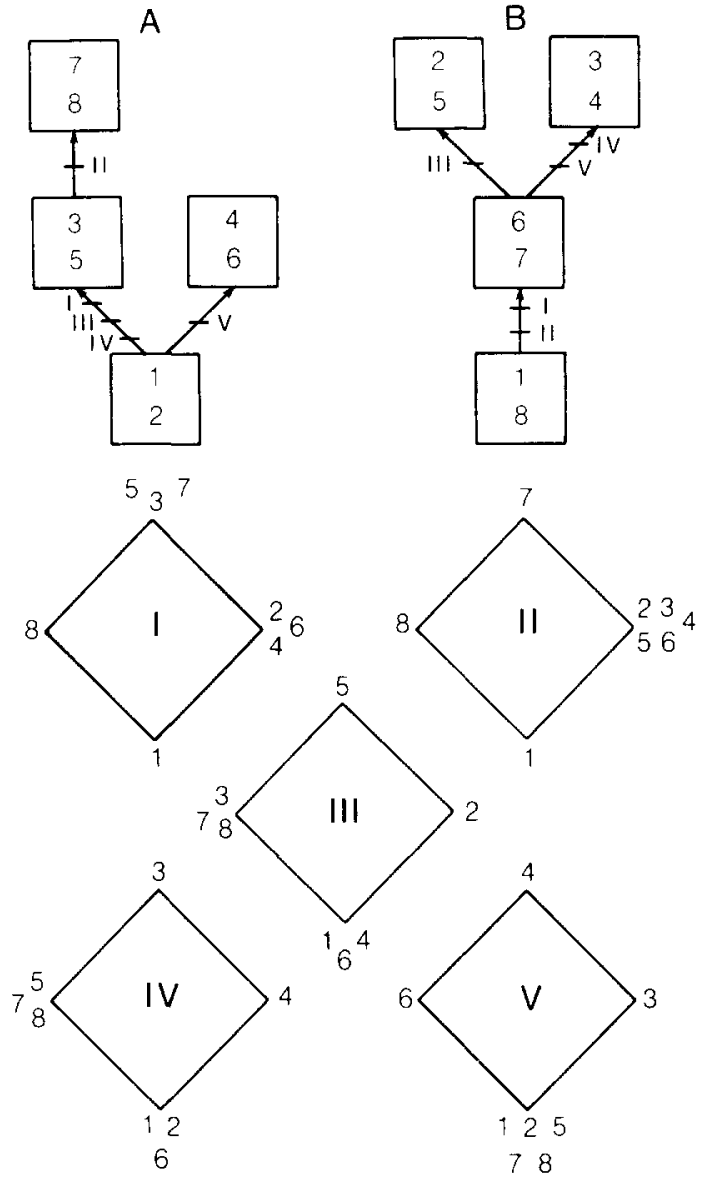

Fig.7. Representation of the complete pairwise conflict between cladistic characters $A$ and $B$, in Fig.5. Five cycles, represented by roman numerals $I-V$, are identified and mapped onto the original cladistic characters. Cycle $I I I$ was identified in Fig.6. 

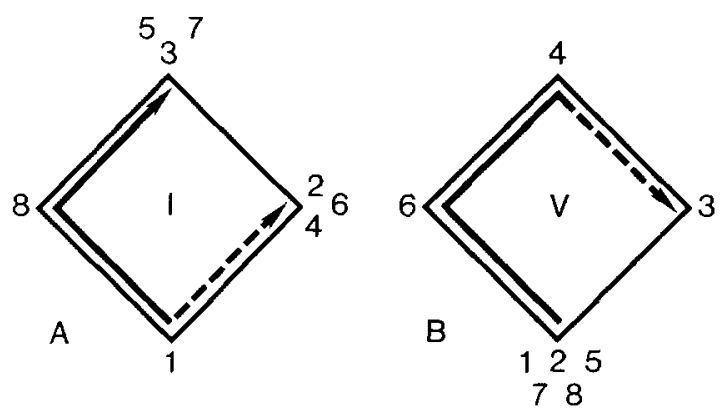

Fig.8. Example resolutions in two of the cycles identified in Fig.7. A. Resolution of cycle $I$ in which it is proposed that the derived state for cladistic character $b$ was achieved in parallel for taxa 3,5 and 7 on the one hand, and 2,4 and 6 on the other. B. Resolution of cycle $V$ in which it is proposed that the primitive state of character $a$ for taxon 3 is the result of reversal from an ancestor with a derived state in $a$.

evidence, bold assertion, and prior assessment, we almost always have some leeway in the structure of a cladistic character, as phylogenetic estimate, we might be willing to accept. We ought to be willing to investigate our uncertainty in the characters by proposing, and then evaluating the logical consequences of, different reasonable formulations of the structural elements. Given what we think we know about the timing of critical evolutionary events, or about the biological nature and likelihood of change in certain features, or plausibility of supporting evidence, for instance, we might have reasons to reformulate proposals of polarity, or polarity and proximity, or polarity and proximity and states, in one or more cladistic characters. It would then be interesting to see how these changes affect our ability to make a combined estimate of phylogeny. Although there is a danger of making circular arguments in such an endeavor, I do not view the whole process as being necessarily so. Indeed, because cladistic characters are rarely equal with regard to evidence, or the kind of arguments used to construct them, it is essential that these different proposals be evaluated. We may use whatever biological or methodological criterion we judge useful in our reformulations. In order to be understood, however, we must be purposeful and explicit in the modifications we make. An attempt at analysis along these lines may be seen in Stein et al. (1984).

\section{Ad hoc measures}

Let me comment briefly on what I view the legitimate use of conflicting cladistic characters to be in the construction of summary statements about relationship. I have suggested above that of all arguments made in phylogenetic analysis (indicated by arrows in Fig.1), those linking cladistic characters with the cladogram should be considered the most purely deductive in mode. Such a view necessarily implies the absolute logical priority of cladistic characters over the cladogram. It is inappropriate in any sense, therefore, to suggest (as I see often written) that a cladogram "falsifies" or, to put it another way, "requires modification" of the cladistic characters used to construct it. This holds true even for those characters that "by reason of parsimony" or any other external consideration become in compatible with the final result. Conflict, when it occurs, arises not between cladogram and cladistic characters, but between the characters themselves as individual phylogenetic estimates. When characters conflict, the idea of using "simplicity of explanation" (measured either as the largest, or in other ways most important set of mutually consistent cladistic characters, see Estabrook et al., 1977; Estabrook and Anderson, 1978; Meacham, 1980, 1984 , or as a minimum number of transitions between character states under some model of permissible transitions, see Camin and Sokal, 1965; Kluge and Farris, 1969; Farris, 1970, 1977; Farris et al., 1970), perhaps, has merit but only in an oblique way. I have little doubt that a very general concept of "parsimony" is applicable to the relationship between the logical (deductive) analysis of characters and the interpretation of empirical evidence (Beatty and Fink, 1979; Farris, 1983; Sober, 1983). However, it is a mistake to equate this concept with any of the above measures, which are clearly ad hoc. The measures may be useful, perhaps, "at first approximation", or "when all 
else fails", but they can never substitute for coming to terms explicitly with the reasons for $w h y$, in terms of biological processes or available evidence, the cladistic characters actually conflict.

\section{The role of fossils in phylogenetic analysis}

Two extreme and opposite views have been expressed, at times, about the significance of paleontological evidence to the reconstruction of phylogenetic patterns (see, for instance, Patterson, 1981; Forey, 1982; Fortey and Jeffries, 1982). They may be summarized as follows:

Fossils will (eventually) tell all - With the collection and study of enough fossils, most, if not all, problems we presently experience in interpreting phylogeny will disappear. Since paleontology is, in a very real sense, the only direct evidence of the past, it should be allowed, when it is able, to supplant other forms of evidence (such as comparative morphology, development, or molecular data), serving in the final analysis as the arbiter of all disputes.

Fossils say nothing (or at least nothing unique) - The fossil record provides, at best, only an expanded range of observable morphol. ogies. Usually, however, this information is incomplete and difficult to compare with much better evidence provided by living specimens. Evidence of age, although suggestive, is subject to error in ways for which we generally cannot control. Thus, paleontological evidence is essentially unreliable, and should be viewed with suspicion in a "critical" analysis of phylogeny.

With arguments like these, intended to relate hypothesis to empirical evidence, it is essential that we ask two questions. First, are the arguments well-formed? That is, do the premises provide at least reasonable grounds for accepting the conclusions? Second, is the asserted relationship between hypothesis and evidence sufficient to encompass what is known, or likely to become known, or is the focus hopelessly narrow? The issues are com- plex, but neither of the above extreme positions survives critical appraisal. In the remainder of this paper, I take an intermediate route - that fossils have an indispensable, but not authoritarian, role to play in phylogenetic analysis. Fossils are a unique form of evidence often underestimated by those unfamiliar with it. On the other hand, as with any scientific endeavor, there are practical limits, at least, to what may be inferred from available evidence, and paleontologists must be careful not to overstate their case. In what follows, I suggest multiple uses for fossil evidence, divided into two general categories: "evidence of morphology" and "evidence of age". Following that, I consider one of the consequences of viewing phylogenetic patterns in biological terms emphasized, perhaps, by the use of fossils: the necessity of treating explicitly the ancestordescendant relationship.

\section{Evidence of morphology}

First and foremost, fossils provide evidence of actual (as opposed to only theoretically possible) morphology simply not obtainable by other means. A particularly good example of the value of fossils may be found in a comparison of recent studies concerning phylogenetic relationships among the major groups of seed plants. The work by Hill and Crane (1982), for example, applied an explicit cladistic approach to the problem, strictly limited to the extant major groups (Fig.9). Compared to a previous study of similar form (Parenti, 1980) which showed serious deficiencies (Smoot et al., 1981), this work is valuable because it makes a wide range of careful comparisons taking full advantage of important recent contributions in the comparative morphology of these groups. However, despite its value, the true dimensions of the problem only become apparent with the addition of fossil evidence. Meyen (1984) and Crane (1985), although differing fundamentally in approach, emphatically agree on at least this point (Figs.10 and 11). I cite two specific examples below.

First, despite the vast array of different 


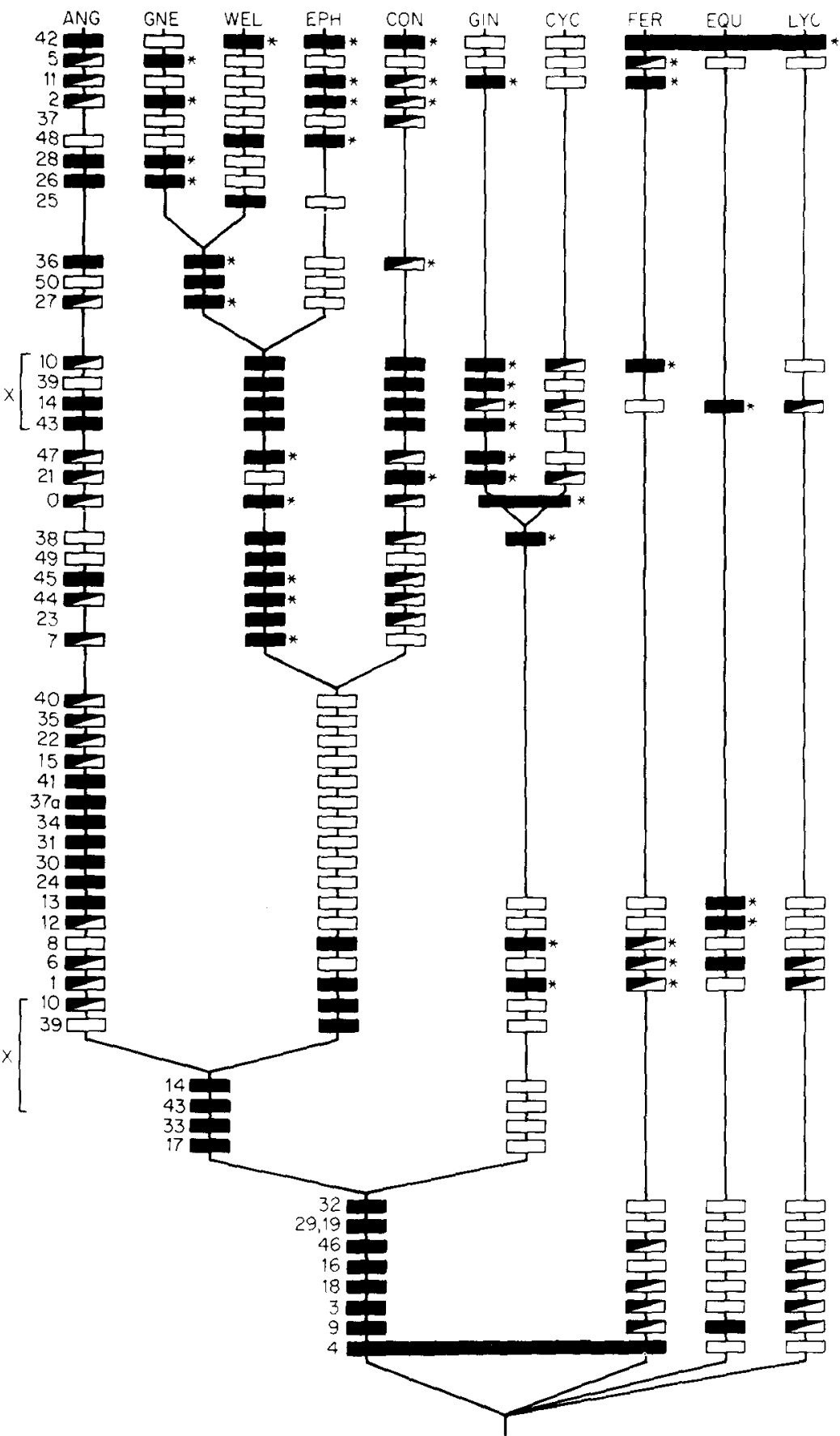

Fig.9. Summary view of relationships of major living groups of vascular plants based on a cladistic analysis using 51 characters. Key to taxa: $A N G=$ angiosperms; $G N E=$ Gnetum; WEL $=$ Welwitschia; $E P H=E p h e d r a ; C O N=$ conifers; $G I N=$ Ginkgo; FER = ferns; $E Q U=$ Equisetum; $L Y C=$ lycopsids. (Reprinted from Hill and Crane, 1982; by permission of the Systematics Association). 


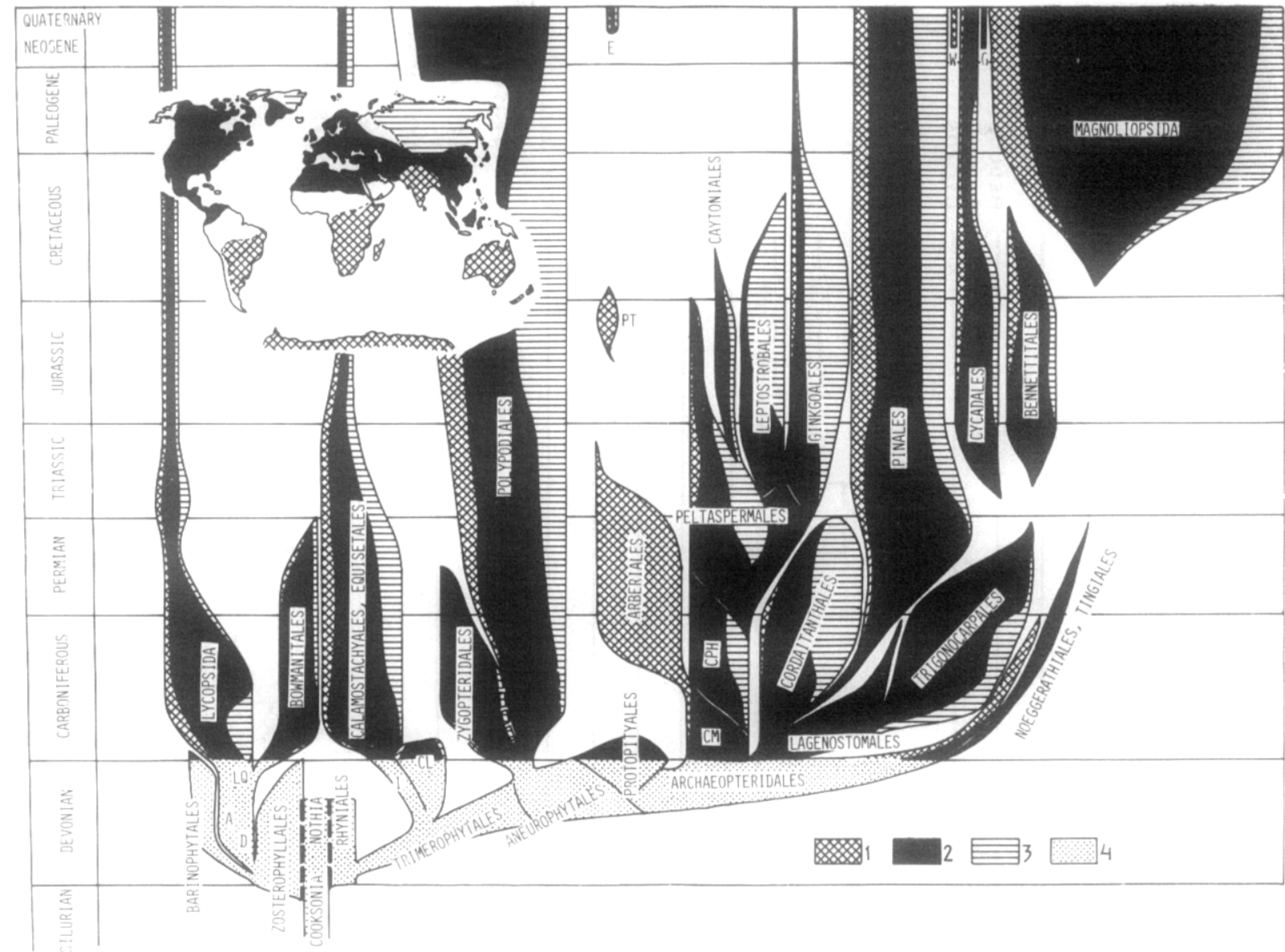

Fig.10. Summary view of the phylogeny of vascular land plants, the result of "congregational analysis" (Meyen, 1984). Key to taxa: $D=$ Drepanophycus; $A=$ Asteroxylon; $L Q=$ Leclercqia $; \quad C L=$ Cladoxylales; $I=$ Ibykales; $C M=$ Calamopityales; $C P H=$ Callistophytales; $P T=$ Pentoxylales; $E=$ Ephedrales; $W=$ Welwitschiales; $G=$ Gnetales; see Meyen for further details. Note that this diagram attempts to summarize phytogeography and diversity in addition to phylogenetic relationships. (Reprinted Meyen (1984); by permission of Botanical Review and The New York Botanical Garden).

living seed plants, the earliest members of this group recognized to date, so-called "seed ferns" belonging to the Paleozoic orders Calamopityales and Lyginopteridales (Taylor, 1981; Taylor and Millay, 1981), are simply not like anything living today. This does not imply, however, that reasonable evidence for shared states is lacking between ancient and living seed plants. Several features, including the "seed" itself, allows us to suggest with confidence at least some relationships (Stewart, 1983; Crane, 1985; Doyle and Donoghue, 1986a).

Second, understanding even the range of morphology observed in early seed plants seems to do little to prepare us for the morphology of their most probable ancestor(s), one or more members of Devonian and Early Carboniferous Progymnospermopsida (Bonamo, 1975; Beck, 1976). Members of this group are considered likely candidates for ancestor because they show unmistakable evidence for shared states with both living and fossil seed plants (notably the presence of "typically gymnospermous" secondary tissues), but they lack some additional derived features characteristic of seed plants [in particular, the "seed" itself (Stein, 1982)].

In both cases, it is safe to say that no amount 


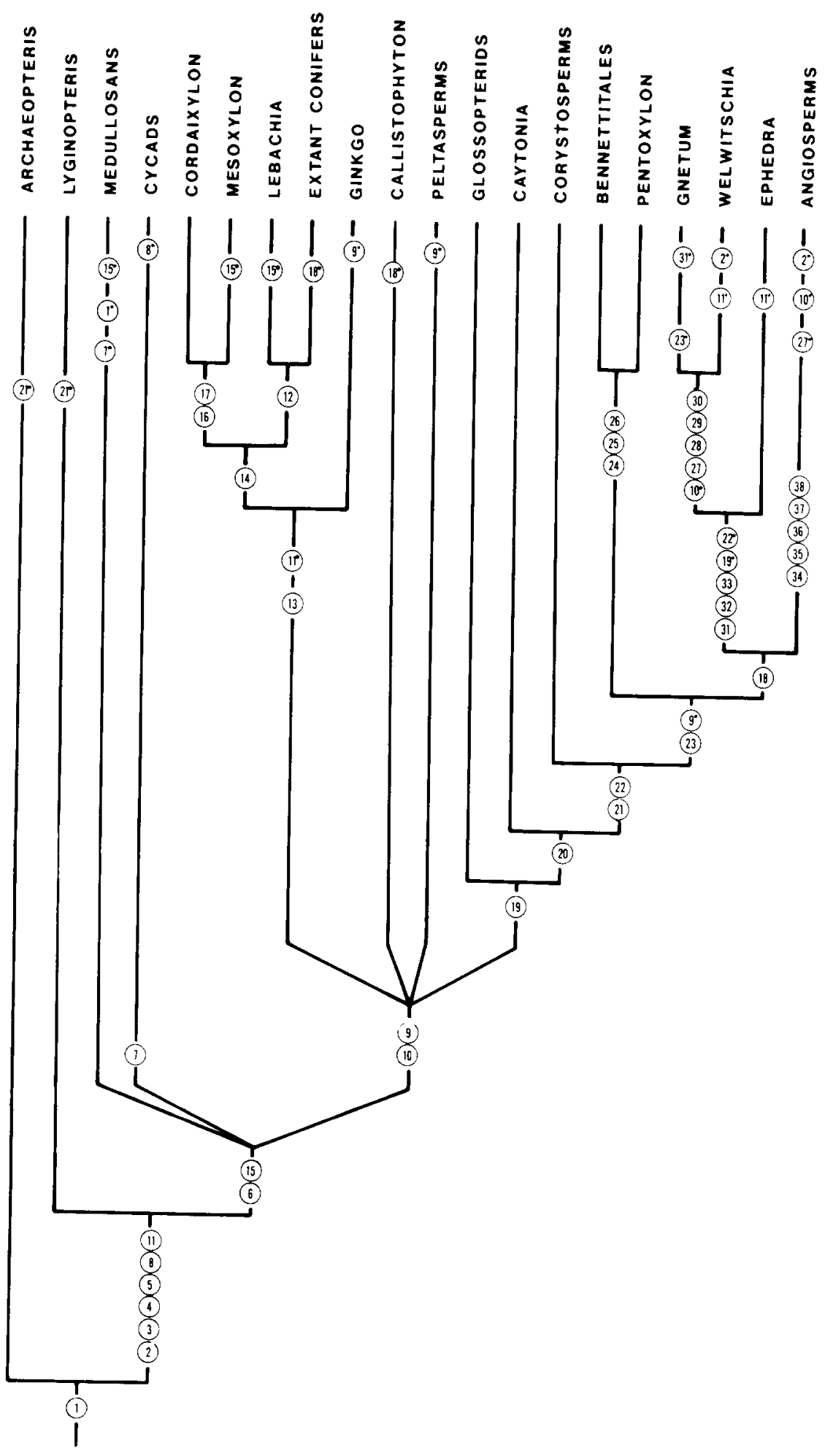


of comparative morphology, based on living taxa, would have allowed us to predict the fossil forms. Yet, the fossils allow us to construct a coherent pattern of morphological diversification and systematic relationships which includes much of what we have learned from comparisons of living plants. This is a strong argument for using a combined approach.

Sometimes, however, fossil evidence complicates what, based on the study of living plants, might be considered a simple pattern of character evolution and relationship (contra Patterson, 1981; see also Doyle and Donoghue, 1986b). For example, two of the most significant features for proposing states in the seed plant clade, based on living plants, are "seed" reproduction, and "eustelic" (or further derived) architecture of the primary vascular system of leafy shoots. Although these features appear unproblematical in the cladistics of living plants (see how they map, for instance, on Figs.9 and 11), an analysis of their distribution within the Lyginopteridales and Progymnospermopsida suggests otherwise (Fig.12). When "seed" and "eustele" are structured as the derived states in simple 2-state cladistic characters for a representative study group (Fig.12, $A, B$ ), the resultant characters are found to be incompatible (Fig.12, C). Possible resolutions of the cycle (see text and Fig.16, below) suggest several alternative phylogenetic hypotheses implying fundamentally different things about the origin of seed plants. In instances like these, the relationship between predictions of ancestral morphology from living forms, and direct evidence from fossils should be clear: in the spirit of the card player (ultimate source unknown), "a peek is worth two finesses".

\section{Form taxa}

As noted above, the fragmentary nature of paleontological evidence, recognized by all, is
A

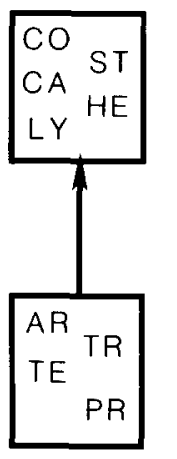

B

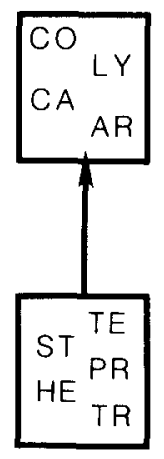

C

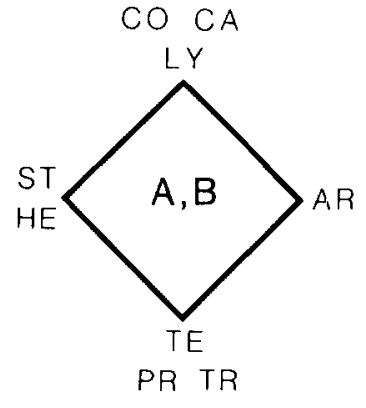

Fig.12. Analysis of "seed" and "eustele" features as derived states in the progymnosperm-seed plant clade. Key to taxa: $C O=$ members of the Coniferales; $C A=$ Callistophyton; $L Y=$ Lyginopteris; $S T=$ Stenomyelon; $H E=$ Heter angium; $A R=$ Archaeopteris; $T E=$ Tetraxylopteris; $T R=$ Triloboxylon; $P R=$ Protopteridium. A. 2-state cladistic character in which the presence of "seed" characterizes the derived state, and "pteridophytic reproduction" [a feature of the progymnosperms (see Bonamo, 1975)] characterizes the primitive state. $B$. 2-state cladistic character in which the presence of the gymnospermous "eustele" or stelar systems judged to be derived from the eustele [like the stelar system of monocots (Beck et al., 1983)] characterize the derived state, and "protostele" characterizes the primitive state. $C$. Cycle showing incompatibility of cladistic characters $A$ and $B$.

used by some to deny it a place in phylogenetic analysis. The argument runs something like the following:

Fossil taxa are usually based on fewer, and often greatly different, characters than are taxa derived from living specimens. In living plants, as opposed to fossil ones, we have access, at least in theory, to all parts of the organism, and all aspects of the life cycle. As a consequence, taxa erected from fossils are not just sometimes (or always) weaker with regard to the evidence supporting them, they are, in fact, fundamentally different and more limited in concept.

I believe this view to be poorly formed and unnecessarily restrictive, but surprisingly, in slightly modified form the argument seems to

Fig.11. Summary view of phylogenetic relationships between major seed plant groups based on a cladistic analysis of representative fossil and living taxa using 38 characters in one of two suggested coding schemes. See Crane (1985) for details. (Reprinted from Crane, 1985; by permission of Annals of the Missouri Botanical Garden). 
count some paleobotanists among its strongest proponents (e.g., Bonamo, 1975; Hughes, 1976; Rothwell and Warner, 1984; Trivett and Rothwell, 1985). In order to make clear what they believe can be inferred about phylogenetic relationship and other biological matters using fossils, these authors stress the distinction between "taxonomic" or "biological" taxa on the one hand, which they conceive to be presently, or once living, "whole plants" with biological/phylogenetic significance, versus "form", or "organ", or "morphological" taxa, on the other hand, which they believe do not have significance. Initially, I interpreted these arguments as simply expressing what is known about taxa as a matter of degree (e.g., Rothwell, 1985), using the "form" or "biological" taxon categories as a means of providing a general estimate of how useful taxa are likely to be in relation to biological and phylogenetic questions. Indeed, I have employed the term "form taxon" in just this way (Stein, 1981, 1982), an inefficient usage, at best, which should be discontinued. Recent statements (Rothwell and Warner, 1984; Trivett and Rothwell, 1985), however, have tended more clearly toward an absolute distinction, that is, one of kind rather than degree.

A distinction-in-kind implies that there is a defensible criterion by which membership in "biological" versus "form" taxa may be judged. However, in no case has there been an explicit attempt to provide such a criterion under this view. The mere formalism of whether a taxon can be assigned to a family or not provided by the International Code of Nomenclature (Voss et al., 1983; see Trivett and Rothwell, 1985) is clearly unsuitable for this purpose. In fossil plants containing several definable organs systems such as "stem", "leaf", "root", and "seed", it might seem reasonable to test for a "biological" taxon-as-kind by insisting on positive evidence of morphology from each major organ system. However, defining what constitutes an "organ system" is a major conceptual problem in plants, and it is important to realize that regardless of the definition proposed, most, if not all, fossil taxa treated as "biologi- cal" by most of us will fail the test. In these cases, we might be tempted to restrict the severity of the test to only a partial set of definable organ systems. For instance, to be considered "biological", we might insist that a particular taxon include positive evidence of "fertile" but not necessarily "vegetative" morphology, or "stem" plus "leaf" but not necessarily "root". However, defining any partial set implies assessing the relative systematic importance of some organ systems compared to others in specific groups, or in plants as a whole. Such assessments would be a priori or, at best, based on only the most tenuous claims to support by evidence.

This state of affairs might be considered reason enough to consider all taxa derived from fossils as "form" taxa, and only presently living plants as "biological" taxa-as-kind (the original proposition). However, it should be recognized that most, if not all, living plant taxa fail the strict test as well. Although, in theory, any aspect of a living plant can be studied for use in systematics, in practice, only a small portion of the phenotype is ever assessed and, as in fossils, there is the definite problem of non-equivalence of information. In countering, it might be argued that one can always re-study living specimens in order to learn whatever one may wish to know about them. However, this becomes important only if there is a corresponding absolute limit on what may potentially become known from fossils. Although there are obvious practical difficulties in the study of fossils compared with that of living plants, no one has provided a convincing argument for why such a limit-in-principle should exist.

Until one does so, I prefer to remain optimistic about what might ultimately become known about fossil taxa. I do so primarily in order to avoid prejudicing myself against looking for new ways to draw biologically meaningful inferences from fossil evidence. It is imperative under such a view that all taxa be considered hypotheses of biology, supported to a greater or lesser degree by evidence, and subject to modification when better evidence becomes 
available. Even traditional "form" taxa, such as Dadoxylon, Stigmaria, Amyelon, or Dolerotheca (the latter's "form" or "biological" status under the code depending on the relatively unimportant decision to recognize the family Medullosaceae in addition to the order Medullosales), must be considered hypotheses of "whole plants" [For a substantially similar view, see Schopf (1978)]. Characters useful in phylogenetic analysis may be extracted from these taxa (see, for instance, Millay and Taylor, 1979; Stidd, 1981; Crane and Manchester, 1982; Doyle et al., 1982) although, of course, what they by themselves are able to suggest about relationships is somewhat limited.

\section{Evidence of age}

The ability of paleontologists to deliver scientifically rigorous age estimates for systematics and other purposes, has been the focus of much recent discussion (Paul, 1982; Behrensmeyer and Schindel, 1983). I shall not attempt a summary here, but two important points relevant to phylogenetic analysis require at least some comment.

First, after more than 150 years of study, the assertion that individual fossil specimens are at least potentially observed in a well-corroborated stratigraphic framework must be considered beyond reproach. The difficulty remains, however, in estimating completeness and resolution of stratigraphic evidence and, in phylogenetic analysis, converting age estimates from single specimens into age estimates for states, or for entire, biologically conceived, paleontological taxa (see also Harper, 1980). Much of the problem with the latter results from difficulty in deciding what, in view of limits to resolution, constitutes at least reasonable grounds for accepting working definitions of both states and taxa in any analysis. Thus, the problem is larger than simply one of assigning age. It is clear that the total number of datable specimens, the inferred biology of the taxa, and some understanding of the processes of sediment deposition, are important factors in providing accurate estimates.
In addition, the time-scale in which such estimates are made also appears significant (Gingerich, 1983).

Second, simply demonstrating by argument (e.g., Eldredge and Cracraft, 1980, pp.55-58), or even by evidence, that age estimates of states or taxa provided by fossils may err in certain circumstances, is insufficient grounds for casting doubt on the utility of the entire line of evidence. The possibility of error is something we simply have to accept in nearly every aspect of phylogenetic analysis. As indicated previously, characters are especially prone to error. Yet no one, so far as I am aware, seriously advocates abandoning all characters simply because some might be in error.

In what follows, I suggest two distinct ways age estimates from fossils impinge on phylogenetic analysis: at the level of "states" in structuring cladistic characters, and at the level of "taxa" in converting cladograms into historically meaningful phylogenetic hypotheses.

\section{Age of states}

When using fossil evidence, the estimates of relative age of states is probably an essential element in making reasonable proximity and polarity assessments for use in structuring cladistic characters (Fig.1, leading to box $D$ ). Several cladists (Schaeffer et al., 1972; Patterson, 1977; Nelson, 1978; Wiley, 1981), have pointed out the danger of using relative age alone in making these estimates. However, the position taken by some of them, attempting to exclude all reference to age in structuring characters, seems equally extreme (Harper, 1976) and, to a degree, off the mark. In the recursive world of phylogenetic analysis, where prior assessment plays such an important role, it is not reasonable to assume that an absolute distinction between these kinds of evidence can always be made, or that the two kinds of evidence, even when recognized, can be separated from each other.

For example, in considering the origin of the Sphenopsida (Stein et al., 1984), three cladistic 
characters were proposed (Fig.13), based on a survey of available evidence linking fossil and living members of this group with fossil taxa judged to be possible ancestors. The entire study group ranged in age from Middle Devonian to Lower Carboniferous. In this work, proximity and polarity relations were estimated using standard outgroup comparison, with the Trimerophytina (in particular, the genus Psilophyton) as the outgroup, and no explicit reference was made to the different ages of the states. However, the choice of Trimerophytina as the outgroup, justifiable on several grounds, is hardly unrelated to age assessments of morphologies of early vascular plants (Chaloner and Sheerin, 1979; Banks, 1968, 1981). Arguments supporting the Trimerophytina are complex and there is little hope of disentangling all concepts of age from this group. Therefore, in cases like this (hardly an isolated example), we are confronted with a choice: either we consider age explicitly in constructing characters (in essence, use age information on states as a check on prior age assessments), or we allow this prior assessment, to input largely uncontrolled. Since the purpose of our study was to evaluate already existing phylogenetic views, we implicitly accepted the prior assessments, and structured our characters accordingly. I now think that

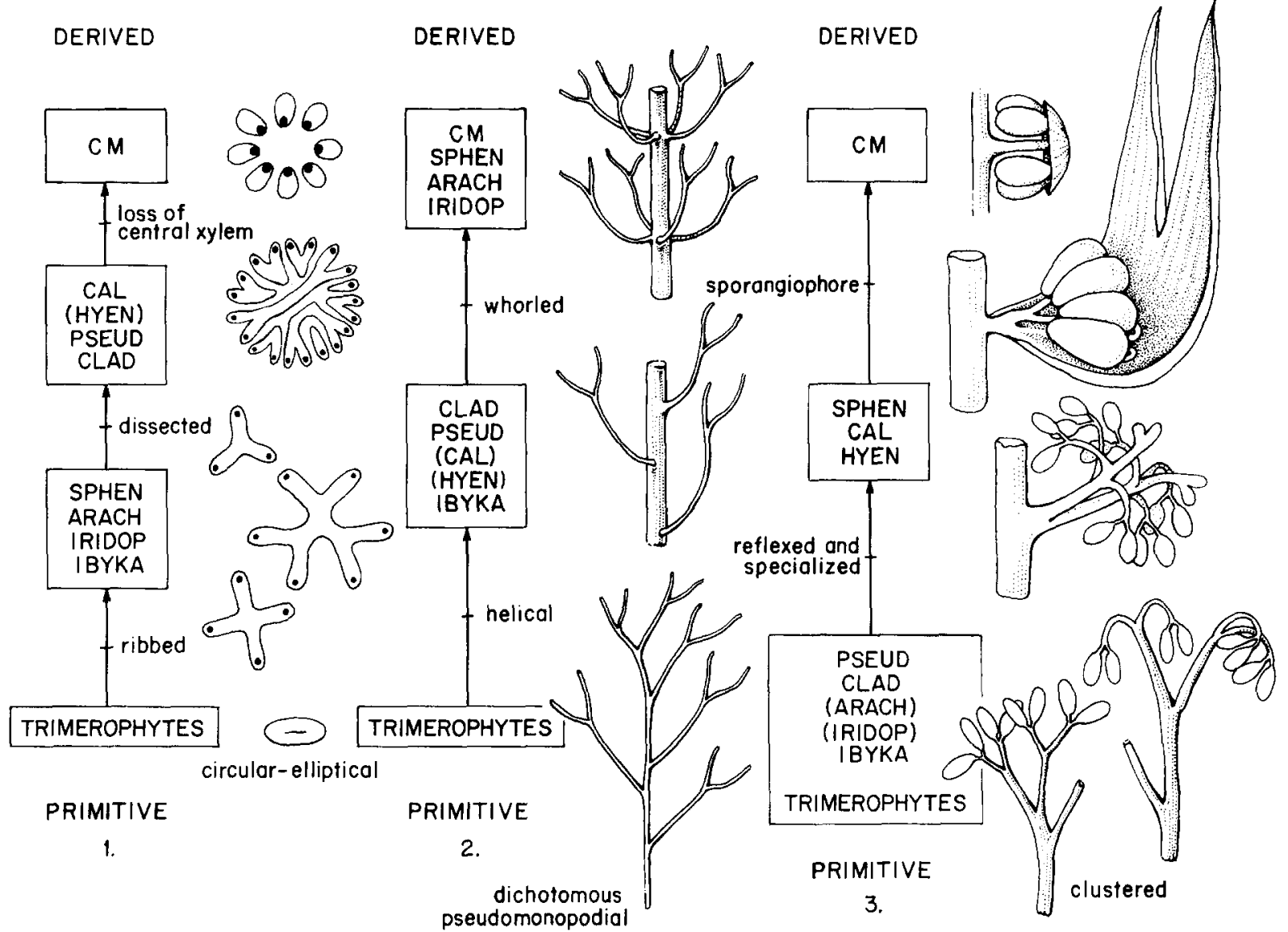

Fig.13. Arguments about the relationship of the Sphenopsida with possible ancestors, structured as three cladistic characters. Key to taxa: $A R A C H=$ Arachnoxylon; $C A L=$ Calamophyton; $C L A D=$ Cladoxylon scoparium; CM=Calamites; HYEN=Hyenia $; I B Y K A=I b y k a ; I R I D O P=$ Iridopteris; $P S E U D=$ Pseudosporochnus; SPHEN=Sphenophyllum. 1. Stelar architecture. 2. Arrangement of lateral appendages. 3. Structure of fertile appendages. (Reprinted from Stein et al., 1983; by permission of Systematic Botany). 
we might have done better to explicitly incorporate age arguments for the states here as well, although I have no reason to believe that doing so would necessarily alter the result in this case. The only other approach to the problem is to dis-allow use of the Trimerophytina (and any other fossil taxon) as the outgroup. However, given the influence fossils have on our view of character evolution and the origin of groups (see above; Doyle and Donoghue, 1986b), simply ignoring evidence can not be the answer. When fossils afford us the luxury of age information, an explicit as possible combination of outgroup analysis and ordering by relative age seems the correct route to take.

\section{Age of taxa}

Even when one makes explicit use of relative age of states in structuring cladistic characters from fossils, not all age information is utilized. The remainder is available for use in a different way (Fig.1, leading to box $F$ ). This is best illustrated by a hypothetical example (Figs.14 and 15). Suppose we have information for the states of two cladistic characters, $A$ and $B$, based on a study group, taxa $1-6$, ranging in age from Lower Devonian through Triassic (Fig.14). Using outside criteria, such as out-
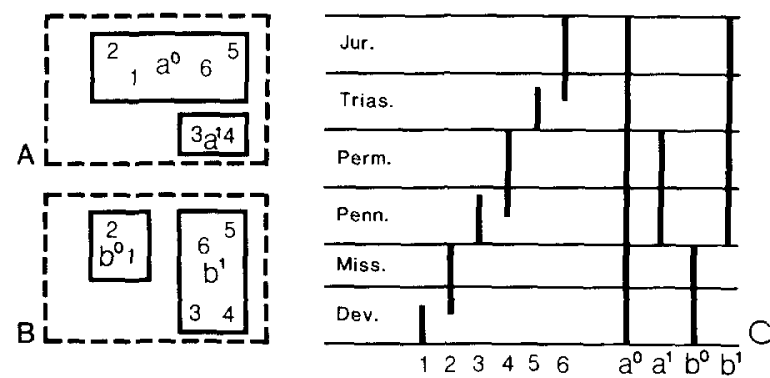

Fig.14. Hypothetical example in which age estimates of taxa may help to further refine phylogenetic estimates. $A$, $B$. It is supposed that two cladistic characters, circumscribed by the dashed boxes, may be defined for taxa $1-6$. It is assumed, further, that states $a^{\circ}$ and $a^{\prime}$ for cladistic character $A$, and states $b^{\circ}$ and $b^{\prime}$ for cladistic character $B$, are recognized as shown by the solid boxes. $C$. Age estimates of taxa and states are plotted on a generalized geological time scale ranging from early Devonian to late Triassic.

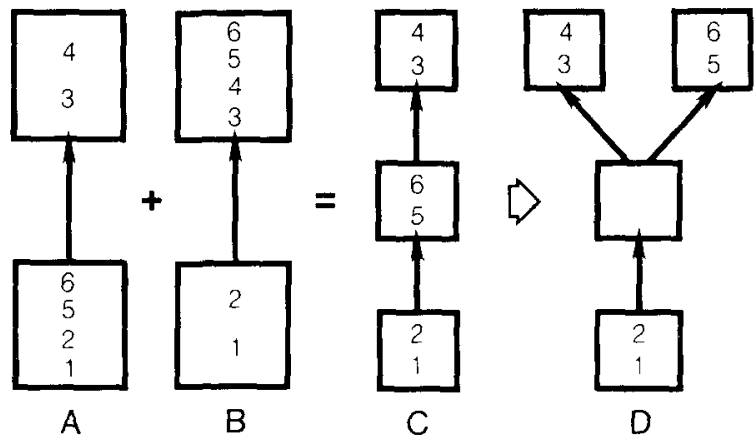

Fig.15. Analysis of phylogenetic relationships of taxa $1-6$ based on character information and age estimates derived from Fig.15. A, B. 2-state cladistic characters polarized in part by reference to age estimates for states. $C$. Cladogram resulting from a combination of compatible cladistic characters $A$ and $B$. D. Phylogenetic hypothesis based on $C$, but consistent with age estimates for entire taxa.

group analysis, plus ordering by age of the states (Fig.14), polarity for each two-state cladistic character might be estimated as shown (Fig.15, $A-B$ ). The cladistic characters in this example turn out to be compatible, and may be combined in a straight-forward manner (Fig.15, C).

In terms of interpreting phylogenetic history, what is the resulting cladogram (Fig.15, C) supposed to mean? I have suggested above that cladistic characters should be considered limited phylogenetic hypotheses [limited "phylogenetic trees" of Eldredge (1979)] in their own right. They are "phylogenetic hypotheses" in the sense that they are intended to be taken literally as estimates of phylogenetic history, but are "limited" because these estimates are based solely on those aspects of morphology and age which can be fitted into the structure of cladistic characters. A cladogram derived deductively from a set of cladistic characters is surely more resolved, but has essentially the same conceptual status. It has only limited historical significance. At the very least, we should attempt to view this result in as precise a historical context as possible.

Following arguments similar to Eldredge (1979) and Fisher (1981), it might be reasonable to consider the cladogram as a kind of shorthand notation specifying a set of possible 
phylogenetic hypotheses (Fig.1, box $F$ ) consistent with the cladistic characters. This set includes not only phylogenetic hypotheses isomorphic with the cladogram, but also hypotheses involving variations on the basic tree structure itself allowing us to consider different branch lengths, any number of hypothetical intermediates, and more explicit assertions about taxa not fully resolved by the cladistic characters (for example, resolving taxon 1 from $2 ; 3$ from $4 ; 5$ from 6 in Figs. 14 and 15). Our job at this point is to evaluate this set for historical plausibility. It is important to note that within this set, some phylogenetic hypotheses, such as a straight-line evolution for taxa 1-6 (isomorphic with Fig.15, C), even though consistent with the age estimates for states, nevertheless, still contradict age estimates for the whole taxa. In view of this fact, it seems reasonable to exclude these hypotheses and accept instead a subset of phylogenetic hypotheses, implied by the summary in Fig.15, $D$, as representing our actual views of phylogeny. Other, more complicated hypotheses involving additional hypothetical intermediates are also plausible, requiring that we adopt a parsimonous approach to our use of this evidence (Harper, 1980; D.C. Fisher, pers. comm., 1986; Doyle et al., 1982). Although there is, at present, a danger of constructing ad hoc rationale for what, in reality, constitutes a conflict between our age and cladistic estimates, arguments like these are sound, but more work toward explicit methods is needed.

In a related line of inquiry, I find particularly exciting the potential use of age estimates in judging the historical plausibility of alternative formulations of state, proximity, and polarity for pairs of cladistic characters known to conflict. For example, consider the conflict between the "seed" and "stele" characters diagrammed in Fig.12. The conflict may be analyzed by considering possible resolutions of the cycle involving small numbers of parallelisms or reversals to account for the distribution of features observed in taxa of the study group (Fig.16). A proposed resolution of this kind modifies state(s) and, as a consequence,
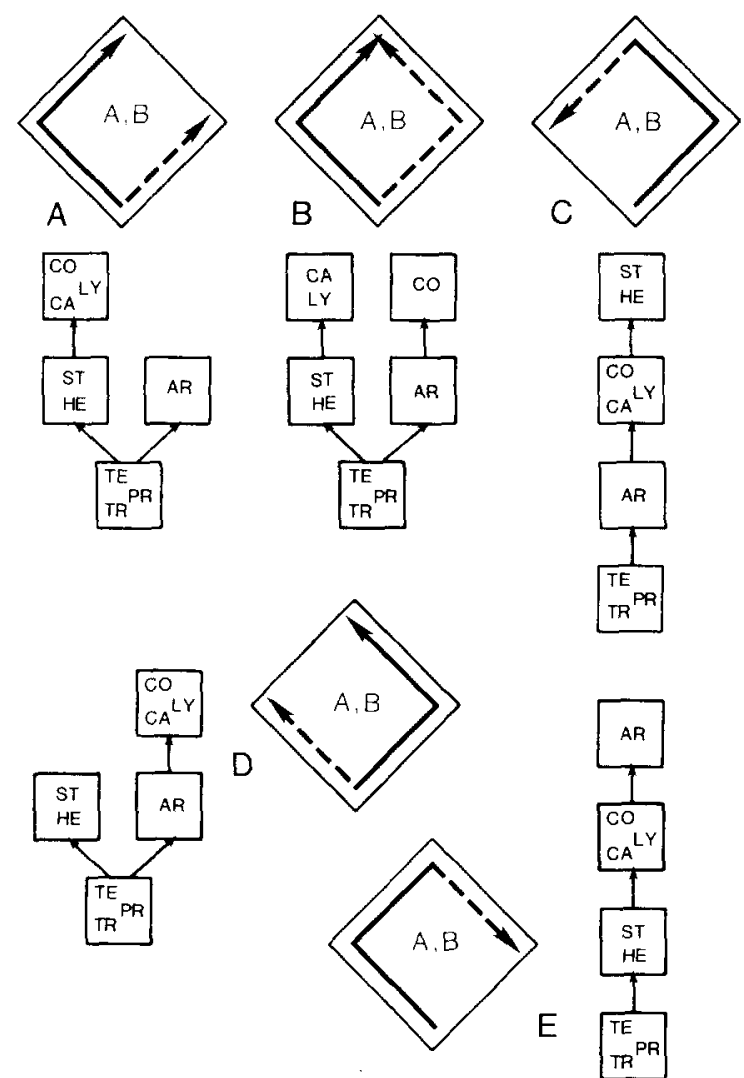

Fig.16. Simple resolutions of the cycle in Fig.12, and resulting cladograms. For a key to taxa, see Fig.12. A. Proposed parallelism in the "stele" character (Fig.12, character B) suggesting that the eustele in Archaeopteris and in seed plants are of independent origin; consistent with the phylogenetic hypothesis of Rothwell (1982). $B$. Proposed parallelisms in both "stele", and "seed" (Fig.12, characters $A$ and $B$ ), suggesting independent origins of eusteles (except for $C O$, same as above), and independent origins of the seed in coniferophytic versus cycadophytic gymnosperms; consistent with the phylogenetic hypothesis of Beck (1981). C. Proposed reversal in the "stele" character suggesting that protosteleic seed plants are derived from eustelic seed plants; see Beck and Stein (1985). D. Proposed parallelism in the "seed" character suggesting independent origin of the seed in protostelic seed ferns on the one hand, and in all other seed plants on the other; except for the placement of Heterangium, consistent with the phylogenetic hypothesis of Meyen (1984). E. Proposed reversal in the seed character suggesting a seed plant origin for Archaeopteris.

also proximity and polarity relations in at least one of the cladistic characters, but in ways that preserve some of our intent in suggesting the characters in the first place. A set of 
cladograms, resulting from considering several possible resolutions of the cycle, may be generated (Fig.16). This set is interesting because some cladograms suggest phylogenetic hypotheses already in the literature (Fig.16, $A$, $B$ ), whereas others suggest alternatives, perhaps, deserving further consideration (Fig.16, $C-E$ ). We may wish to reject some cladograms, or phylogenetic hypotheses, on the grounds that parallelisms or reversals in some features are more (or less) likely than in others. These arguments stand or fall on whatever evidence one might have to back up the claims, in many cases not much. Judging the historical plausibility of the cladograms based on age, however, seems to be of some assistance in evaluating these alternative character formulations. Three cladograms (Fig.16, $A, B, D$ ), viewed directly as phylogenetic hypotheses, are consistent with stratigraphic evidence for whole taxa (Fig.17). One cladogram (Fig.16, C) implies a set of phylogenetic hypotheses that is only partially consistent. Only phylogenetic hypotheses which remove the $\{C O, C A, L Y\}$ state from the main line, and replace it with a hypothetical intermediate, are viable. The remaining cladogram (Fig.16, E) implies a set of phylogenetic hypotheses all of which conflict with stratigraphic evidence. The resolved cycle suggests that Archaeopteris arose from some seed plant. However, Archaeopteris significantly predates not only seed plants of the study group, but also any credible evidence whatsoever of seed plants in Devonian sediments (Banks, 1981).

\section{Ancestors and descendants}

The use of fossils in phylogenetic analysis tends to emphasize a fact that is generally true for all biological taxa, namely that they are, or were, the actual participants in the evolution. ary patterns and processes we are trying to understand. It is imperative that we adopt an approach to taxa in phylogenetic analysis that recognizes this fact. As a result, I suggest that the very specific and very important concepts of candidate for ancestor and candidate for

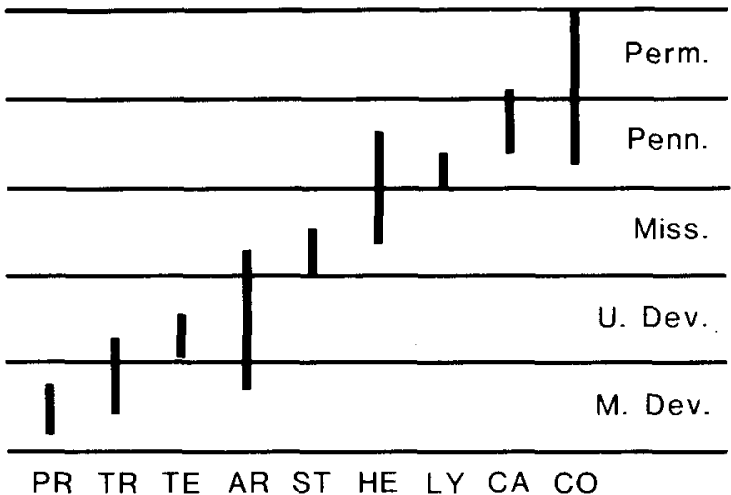

Fig.17. Age estimates for taxa analyzed in Figs.12 and 16, plotted on a generalized geological time scale from early Middle Devonian to late Permian. For a key to taxa, see Fig.12. (Age estimates derived from Read, 1937; Beck, 1957, 1976; Banks, 1966, 1980; Rothwell, 1975, 1982; Shadle and Stidd, 1975; Bonamo, 1977; Taylor and Millay, 1981; Schweitzer and Matten, 1982; Stein et al., 1983; Scott et al., 1984).

descendant have a vital role to play in nearly every aspect of the formulation of phylogenetic hypotheses.

Cladists, in general, have been hesitant to treat the possibility of identifying ancestors. To a large extent, their reluctance is due to difficulties in notation (i.e., being able to unambiguously represent the relationship within a traditional Hennigian "argumentation scheme" or similar system; Hull, 1980). They are also put off by the long history of imprecision and misuse of these concepts in phylogenetic work (Patterson, 1981; Forey, 1982). These problems, although serious, are by no means insurmountable. Several cladists have suggested a more fundamental problem, however, when they term the ancestordescendant relationship an "unfalsifiable" or "weakly falsifiable" concept (Engelmann and Wiley, 1977; Gaffney, 1979). According to this view, specific taxa, even if well-known morphologically and temporally, can never be demonstrated with certainty to belong to the relationship. The recommendation has been, therefore, to abandon the search for the ancestors (and often with it, the use of fossils), and concentrate instead on sister groups or set relations supported by "synapomorphies" and inter- 
preted, only if one wishes, as having historical significance (Patterson, 1982; Brady, 1985). Although some cladists (e.g., Wiley, 1981, p.107) have recently tempered their views as a result of criticism directed at both the logic and empirical content of their arguments (Szalay, 1977; Hull, 1979, 1980; Cartmill, 1981), suspicion of ancestors remains widespread.

The failure to treat the ancestor-descendant relationship explicitly in a cladistic method represents an attempt to "solve" a significant methodological problem by choosing to ignore it. If we accept at least some basic tenets of Darwinian theory, in particular the concept of descent with modification, then it appears that the ancestor-descendant relationship constitutes a fundamental aspect of phylogeny to be "discovered" by any method. The failure of a particular method to address the relationship is, as a result, to be considered a weakness of the method (Hull, 1980). Some argue, however, that there is no place for evolutionary theory in the conceptual framework of methods for discovering "patterns" in nature (Patterson, 1982; Brady, 1983, 1985). This view seemingly obviates consideration of the ancestor-descendant relationship, but unfortunately, it also sacrifices any claim for the utility of particular methods employed (cladistic versus phenetic, for instance) as well as any claim for relevance of the pattern "discovered" to biological questions.

In the view presented here, the concepts of candidate for ancestor and candidate for descendant stand in the same relationship to empirical evidence as do other phylogenetic hypotheses. The requirement of demonstration for the relationship, in a deductive sense as suggested above, is clearly unnecessary. Fossil and living specimens provide evidence that certain morphologies out of a large range of theoretical possibilities actually existed in the history of life. Fossils, in addition, provide estimates of age for taxa and states. From this, hypotheses of ancestor-descendant relationship may be constructed. Like other phylogenetic hypotheses, there is always the possibility for error. With additional empirical dence, however, it may be possible to detect these errors or, otherwise, estimate the relative confidence with which we hold certain views. Arguments involving the ancestordescendant relationship, like those covering other phylogenetic hypotheses, are partly addressed by the hypothetico-deductive, or "strong inference" (Platt, 1964) format: A certain biologically conceived taxon, either because of observed morphology or evidence of age, can with some confidence be ruled out as the ancestor of another. Repeated failure in attempts to falsify, leaves one with an excellent candidate for ancestor and an empirical base for what, in fact, we really wish to know.

\section{Summary and conclusions}

In this review, few ideas can be claimed as totally new. Some instances where I deviate from "common" or "accepted" views, however, are summarized in the following paragraphs.

The idea of a formal analogy between what we do in phylogenetic analysis, and recursive functions in mathematics, has been suggested obliquely in several sources but, to my knowledge, has never been given explicit statement. The analogy has much to offer. Certainly, the distinction between circular reasoning and repetitive analysis, the hallmark of recursion, is a fundamental one to make. Studies of computation and artificial intelligence, moreover, suggest that we must not underestimate the power of recursive processes, not only in the complexity they generate, but also the unpredictability of result. Biologists should take note. The "fit" of recursion with innumerable "feed-back" processes, and even cognitive activities like "reciprocal illumination" (Hennig, 1966), is likely to be a close one.

Despite claims to the contrary and much discussion, "Popperian" systematists have not solved the long-standing "Problem of Induction". This view is by no means new here. However, with the spread of more explicit methods and, perhaps more importantly, the increasingly common use of the computer (and 
associated massive "data" sets) in systematics, it is more essential than ever that we consider carefully the "logic" of what we are trying to do. We must be explicit about which assertions are considered evidence for particular phylogenetic views (i.e., the premises of deductive or inductive arguments leading to phylogenies), and which others constitute interpretation (the conclusions of deduction or induction from a given phylogenetic viewpoint). I suggest here that the relationship between cladistic charac ters and the cladogram should be considered a straightforward deductive step. Those who suggest a more complicated arrangement (and there are many) must distinguish their method from trivial restructuring of characters in the face of conflict.

By far the most important aspects of any cladistic analysis are the assessments of biology and available evidence that serve as the premise for a phylogenetic view. This assertion is certainly not new, but tends to be underemphasized in some cladistic studies. Proposing a formal and explicit structure to cladistic characters along the lines suggested here allows one to scrutinize and debate in detail at least some aspects of the evidence base. When phylogenetic estimates conflict (as is often the case), we must recognize the conflict as such and be willing to consider the plausibility of alternative formulations. We must not allow ad hoc measures, offered "for simplicity's sake", to make the important decisions for us.

When available, fossils have an indispensable, although not authoritarian, role to play in phylogenetic analysis. Fossils provide evidence of morphology simply not available by other means. Everything we observe in fossils, however, must be subject to biological interpretation. In phylogenetic analysis, there seems to be little justification for the common paleobotanical practice of distinguishing "form" from "biological" taxa. Paleobotanists might do well to reconsider whether the practice serves any purpose at all.

Because of recursion in our science, reference to age, much maligned by some cladists, is probably unavoidable when using fossil mater- ial. This is not necessarily a handicap, but must be acknowledged and properly managed. I suggest that age estimates from fossils input into phylogenetic analysis in at least two distinct ways. The first is in proposing historically plausible ordering for "states" of individual cladistic characters. The second involves trying to visualize the historical context of a cladogram by considering the set of specific phylogenetic hypotheses for biologically conceived taxa that it represents. There is room for more explicit methods here, but in order to take full advantage of the historical significance of fossils, attempts in this direction must be made.

Finally, if our purpose in doing phylogenetic analysis is to help answer evolutionary questions, then we should be unwilling to accept any phylogenetic method that stops short of treating realistically the ancestor-descendant relationship. Armed with the concepts of "candidate for ancestor" and "candidate for descendant", I suggest that the relationship is addressed in the same way as all other phylogenetic hypotheses. One may never be able to offer absolute proof that one taxon is ancestral to another. However, we must attempt to state clearly, in terms of character evidence or age, why certain taxon-pairs are unlikely to belong to the relationship.

\section{Acknowledgements}

I wish to thank G. Estabrook for providing the stimulus for much of the perspective on characters developed here. For helpful discussion, I thank B. Beall, C. Beck, M. Cichan, D. Fisher, A. Kluge, G. Mapes, C. Miller, A. Treiman (my source for the card player's homily), D. Wight, and members of the "student" discussion group, Museum of Paleontology, University of Michigan. Useful comments on earlier drafts were made by B. Beall, C. Beck, P. Crane, M. Donoghue, D. Fisher, G. Rothwell, and D. Wight. Supported by NSF grant BSR- 8306893 to W. Stein and C. Beck. 


\section{References}

Banks, H.P., 1966. Devonian flora of New York State. Emp. State Geogr., 4: 10-24.

Banks, H.P., 1968. The early history of land plants. In: E.T. Drake (Editor), Evolution and Environment. Yale Univ. Press, New Haven, Conn., pp.73-107.

Banks, H.P., 1980. Floral assemblages in the SiluroDevonian. In: D.L. Dilcher and T.N. Taylor (Editors), Biostratigraphy of Fossil Plants. Dowden, Hutchinson, and Ross, Stroudsburg, Pa., pp.1-24.

Banks, H.P., 1981. Time of appearance of some plant biocharacters during Siluro-Devonian time. Can. J. Bot., 59: $1292-1296$.

Beatty, J., 1982. Classes and cladists. Syst. Zool., 31: 25-34.

Beatty, J. and Fink, W.L., 1979. Review of: Simplicity, by E. Sober, 1975, Clarendon Press, Oxford. Syst. Zool., 28: 643-651.

Beck, C.B., 1957. Tetraxylopteris schmidtii gen. et sp. nov., a probable pteridosperm precursor from the Devonian of New York. Am. J. Bot., 44: 350-367.

Beck, C.B., 1976. Current status of the Progymnospermopsida. Rev. Palaeobot. Palynol,, 21: 5-23.

Beck, C.B., 1981. Archaeopteris and its role in vascular plant evolution. In: K.J. Niklas (Editor), Paleobotany, Paleoecology, and Evolution, Vol. 2. Praeger, New York, N.Y., pp.193-230.

Beck, C.B. and Stein, W.E., 1985. Eustelic protosteles in early seed plants? Am. J. Bot., 72: 889-890.

Beck, C.B.. Schmid, R. and Rothwell, G.W., 1983. Stelar morphology and the primary vascular system of seed plants. Bot. Rev., 48: 681-815.

Behrensmeyer, A.K. and Schindel, D., 1983. Resolving time in paleobiology. Paleobiology, 9: 1-8.

Bock, W.J., 1974. Philosophical foundations of classical evolutionary classification. Syst. Zool., 22: 375-392.

Bonamo, P.M., 1975. The Progymnospermopsida: building a concept. Taxon, 24: 569-579.

Bonamo, P.M., 1977. Rellimia thomsonii (Progymnospermopsida) from the Middle Devonian of New York State. Am. J. Bot., 64: 1272-1285.

Brady, R.H., 1983. Parsimony, hierarchy, and biological implications. In: N.I. Platnick and V.A. Funk (Editors), Advances in Cladistics, Vol. 2. Columbia Univ. Press, New York, N.Y., pp.49-60.

Brady, R.H., 1985. On the independence of systematics. Cladistics, 1: 113-126.

Braithwaite, R.B., 1955. Scientific Explanation. Cambridge Univ. Press, Cambridge, 376 pp.

Burks, A.W., 1977. Chance, Cause, Reason. Univ. Chicago Press, Chicago, 694 pp.

Camin, J.H. and Sokal, R.R., 1965. A method for deducing branching sequences in phylogeny. Evolution, 19: 311-326.

Cartmill, M., 1981. Hypothesis testing and phylogenetic reconstruction. Z. Zool. Syst. Evolutionsforsch., 19: $73-96$.
Chaloner, W.G. and Sheerin, A., 1979. Devonian macrofloras. Spec. Pap. Palaeontol., 23: 145-161.

Copi, I.M., 1978. Introduction to Logic. MacMillan, New York, N.Y., $590 \mathrm{pp}$.

Crane, P.R., 1984. Misplaced pessimism and misguided optimism: a reply to Mabberley. Taxon, 33: 79-82.

Crane, P.R., 1985. Phylogenetic analysis of seed plants and the origin of angiosperms. Ann. Mo. Bot. Gard., 72: 716-793.

Crane, P.R. and Manchester, S.R., 1982. An extinct juglandaceous fruit from the Upper Palaeocene of southern England. Bot. J. Linn. Soc., 85: 89-101.

Cutland, N., 1980. Computability. Cambridge Univ. Press, Cambridge, $251 \mathrm{pp}$.

DiMichele, W.A., 1985. The upward outlook in paleobotany. Paleobiology, 11: 356-359.

Donoghue, M.J. and Cantino, P.D., 1984. The logic and limitations of the outgroup substitution approach to cladistic analysis. Syst. Bot., 9: 192-202.

Doyle, J.A. and Donoghue, M.J., 1986a. Seed plant phylogeny and the origin of angiosperms: an experimental approach. Bot. Rev. (in press).

Doyle, J.A. and Donoghue, M.J., 1986b. The importance of fossils in elucidating seed plant phylogeny and macroevolution. Rev. Palaeobot. Palynol,, 50: 63-96.

Doyle, J.A., Jardine, S. and Doerenkamp, A., 1982. Afropollis, a new genus of early angiosperm pollen, with notes on the Cretaceous palynostratigraphy and paleoenvironments of northern Gondwana. Bull. Cent. Rech. Explor.Prod. Elf-Aquitaine, 6: 39 117.

Eldredge, N., 1979. Cladism and common sense. In: J. Cracraft and N. Eldredge (Editors), Phylogenetic Analysis and Paleontology. Columbia Univ. Press, New York, N.Y., pp.165-198.

Eldredge, N. and Cracraft, J., 1980. Phylogenetic Patterns and the Evolutionary Process. Columbia Univ. Press, New York, N.Y., 349 pp.

Engelmann, G.F. and Wiley, E.O., 1977. The place of ancestor descendant relationships in phylogeny reconstruction. Syst. Zool., 26: 1-11.

Estabrook, G.F., 1978. Some concepts for the estimation of relationships in systematic botany. Syst. Bot., 3: 146-158.

Estabrook, G.F., 1983. The causes of character incom patibility. In: J. Felsenstein (Editor), Numerical Tax onomy (NATO ASI Ser., Gl.). Springer, Berlin, pp.279-295.

Estabrook, G.F. and Anderson, W.R., 1978. An estimate of phylogenetic relationships within the genus Crusea (Rubiaceae) using character compatibility analysis. Syst. Bot., 3: 179-196.

Estabrook, G.F., Johnson, C.S. and McMorris, F.R., 1976. A mathematical foundation for the analysis of cladistic character compatibility. Math. Biosci., 29: 181-187.

Estabrook, G.F., Strauch, J.G. and Fiala, K.L., 1977. An application of compatibility analysis to the Blackiths' data on orthopteroid insects. Syst. Zool., 26: 269-276. 
Farris, J.S., 1970. Methods for computing Wagner trees. Syst. Zool., 19: 83-92.

Farris, J.S., 1977. Phylogenetic analysis under Dollo's law. Syst. Zool., 26: 77-88.

Farris, J.S., 1983. The logical basis of phylogenetic analysis. In: N.I. Platnick and V.A. Funk (Editors), Advances in Cladistics, Vol. 2. Columbia Univ. Press, New York, N.Y., pp.7-36.

Farris, J.S., Kluge, A.G. and Eckardt, M.J., 1970. A numerical approach to phylogenetic systematics. Syst. Zool., 19: 172-191.

Felsenstein, J., 1982. Numerical methods for inferring evolutionary trees. Q. Rev. Biol., 57: 379-404.

Feyerabend, P., 1975. Against method. Thetford Press, Thetford, Verso edition, $339 \mathrm{pp}$.

Fisher, D.C., 1981. The role of functional analysis in phylogenetic inference: examples from the history of the Xiphosura. Am. Zool, 21: 47-62.

Fisher, D.C., 1982. Phylogenetic and macroevolutionary patterns within the Xiphosurida. Proc. 3rd North Am. Paleontol. Conv., 1: 175-180.

Forey, P.L., 1982. Neontological analysis versus paleontological stories. In: K.A. Joysey and A.E. Friday (Editors), Problems of Phylogenetic Reconstruction. Syst. Assoc., 21: 119-157.

Fortey, R.A. and Jeffries, R.P.S., 1982. Fossils and phylogeny - a compromise approach. In: K.A. Joysey and A.E. Friday (Editors), Problems of Phylogenetic Reconstruction. Syst. Assoc., 21: 197-234.

Gaffney, E.S., 1979. An introduction to the logic of phylogeny reconstruction. In: J. Cracraft and N. EIdredge (Editors), Phylogenetic Analysis and Paleontology. Columbia Univ. Press, New York, N.Y., pp.79-111.

Gingerich, P.D., 1974. Size variability of the teeth in living mammals and the diagnosis of closely related sympatric fossil species. J. Paleontol., 48: 895-903.

Gingerich, P.D., 1979. The stratophenetic approach to phylogeny reconstruction in vertebrate paleontology. In: J. Cracraft and N. Eldredge (Editors), Phylogenetic Analysis and Paleontology. Columbia Univ. Press, New York, N.Y., pp.41-77.

Gingerich, P.D., 1983. Rates of evolution: effects of time and temporal scaling. Science, 222: 159-161.

Gould, J.A., 1985. Classic Philosophical Questions. Merrill, Columbus, Ohio, 5th Ed., 728 pp.

Harper, C.W., 1976. Phylogenetic inference in paleontology. J. Paleontol., 50: 180-193.

Harper, C.W., 1979. A Bayesian probability view of phylogenetic systematics. Syst. Zool., 28: 547-553.

Harper, C.W., 1980. Relative age inference in paleontology. Lethaia, 13: 239-248.

Harper, C.W. and Platnick, N.I., 1978. Phylogenetic and cladistic hypotheses: a debate. Syst. Zool., 27: 354-362.

Hennig, W., 1966. Phylogenetic Systematics. Univ. Illinois Press, Urbana, Ill., 263 pp.

Hill, C.R. and Crane, P.R., 1982. Evolutionary cladistics and the origin of angiosperms. In: K.A. Joysey and A.E.
Friday (Editors), Problems of Phylogenetic Reconstruction. Syst. Assoc., 21: 269-361.

Hofstadter, D.R., 1980. Godel, Escher, Bach: An Eternal Golden Braid. Vantage Books, New York, N.Y., 777 pp.

Hughes, N.F., 1976. Palaeobiology of Angiosperm Origins. Cambridge Univ. Press, Cambridge, $242 \mathrm{pp}$.

Hull, D.L., 1967. Certainty and circularity in evolutionary taxonomy. Evolution, 21: 174-189.

Hull, D.L., 1979. The limits of cladism. Syst. Zool., 28: 416-440.

Hull, D.L., 1980. Cladism gets sorted out. Paleobiology, 6: 131-136.

Hull, D.L., 1983. Karl Popper and Plato's metaphor. In: N.I. Platnick and V.A. Funk (Editors), Advances in Cladistics, Vol. 2. Columbia Univ. Press, New York, N.Y., pp.201-211.

Hume, D., 1748. An Inquiry Concerning Human Understanding. In: C.W. Hendel (Editor), 1955. Bobbs-Merril, Indianapolis, Ind., $198 \mathrm{pp}$.

Humphries, C.J., 1983. Primary data in hybrid analysis. In: N.I. Platnick and V.A. Funk (Editors), Advances in Cladistics, Vol. 2. Columbia Univ. Press, New York, N.Y., pp.89-103.

Jeffrey, R., 1981. Formal Logic. McGraw-Hill, New York, N.Y., $198 \mathrm{pp}$

Jensen, R.J., 1983. A practical view of numerical taxonomy or should I be a pheneticist or cladist? In: J. Felsenstein (Editor), Numerical Taxonomy (NATO ASI Series, Gl). Springer, Berlin, pp.53-71.

Kant, I., 1787. Critique of Pure Reason. Macmillan, London, 681 pp. (Translated by: N.I. Smith, 1933.)

Kitts, D.B., 1977. Karl Popper, verifiability, and systematic zoology. Syst. Zool., 26: 185-194.

Kluge, A.G. and Farris, J.S., 1969. Quantitative phyletics and the evolution of Anurans. Syst. Zool., 18: 1-32.

Kolenda, K., 1974. Philosophy's Journey: A Historical Introduction. Addison-Wesley, Reading, Mass., $372 \mathrm{pp}$.

Kuhn, T.S., 1970. The Structure of Scientific Revolutions. Univ. Chicago Press, Chicago, Ill., 210 pp.

Kyburg, H.E., 1970. Probability and Inductive Logic. Macmillan, London, 272 pp.

Lakatos, I., 1978. The Methodology of Scientific Research Programmes. In: J. Worrall and G. Currie (Editors). Cambridge Univ. Press, Cambridge, $250 \mathrm{pp}$.

Lakatos, I. and Musgrave, A. (Editors), 1970. Criticism and the Growth of Knowledge. Cambridge Univ. Press, Cambridge, $282 \mathrm{pp}$.

Laudan, L., 1977. Progress and Its Problems. Univ. California Press, Berkeley, Calif., 257 pp.

LeQuesne, W.J., 1969. A method of selection of characters in numerical taxonomy. Syst. Zool., 18: 201-205.

Maddison, W.P., Donoghue, M.J. and Maddison, D.R., 1984. Outgroup analysis and parsimony. Syst. Zool., 33: 83-103.

McNaughton, R., 1982. Elementary Computability, Formal Languages, and Automata. Prentice-Hall, Englewood Cliffs, N.J., 400 pp. 
Meacham, C.A., 1980. Phylogeny of the Berberidaceae with an evaluation of classifications. Syst. Bot., 5: 149-172.

Meacham, C.A., 1984. Evaluating characters by character compatibility analysis. In: T. Duncan and T. Stuessy (Editors), Cladistics: Perspectives on the Reconstruction of Evolutionary History. Columbia Univ. Press, New York, N.Y., pp.152-165.

Meyen, S.V., 1984. Basic features of gymnosperm systematics and phylogeny as evidenced by the fossil record. Bot. Rev., 50: 1-111.

Millay, M.A. and Taylor, T.N., 1979. Paleozoic seed fern pollen organs. Bot. Rev., 45: 301-375.

Nelson, G., 1978. Ontogeny, phylogeny, paleontology, and the biogenetic law. Syst. Zool., 27: 324-345.

Nelson, G., 1983. Reticulation in cladograms. In: N.I. Platnick and V.A. Funk (Editors), Advances in Cladistics, Vol. 2. Columbia Univ. Press, New York, N.Y., pp.105-111.

Nelson, G. and Platnick, N., 1981. Systematics and Biogeography. Columbia Univ. Press, New York, N.Y., $567 \mathrm{pp}$.

Newton-Smith, W.H., 1981. The Rationality of Science. Routledge and Kegan Paul, Boston, Mass., 294 pp.

Niklas, K.J. and Gensel, P.G., 1982. Chemotaxonomy of some Paleozoic vascular plants. Part III. Cluster configurations and their bearing on taxonomic relationships. Brittonia, 30: 216-232.

Parenti, L.R., 1980. A phylogenetic analysis of the land plants. Biol. J. Linn. Soc., 13: 225-242.

Patterson, C., 1977. The contribution of paleontology to teleostean phylogeny. In: M.K. Hecht, P.C. Gooday and B.M. Hecht (Editors), Major Patterns in Vertebrate Evolution. Plenum Press, New York, N.Y., pp.579-643.

Patterson, C., 1981. Significance of fossils in determining evolutionary relationships. Ann. Rev. Ecol. Syst., 12: 195-223.

Patterson, C., 1982. Morphological characters and homology. In: K.A. Joysey and A.E. Friday (Editors), Problems of Phylogenetic Reconstruction. Syst. Assoc., 21: 21-74.

Paul, C.R.C., 1982. The adequacy of the fossil record. In: K.A. Joysey and A.E. Friday (Editors), Problems of Phylogenetic Reconstruction. Syst. Assoc., 21: 75-117.

Péter, R., 1981. Recursive Functions in Computer Theory. Ellis Horwood, Chichester, 179 pp.

Platnick, N.I. and Gaffney, E.S., 1978a. Evolutionary biology: a Popperian perspective. Syst. Zool., 27: 137-141.

Platnick, N.I. and Gaffney, E.S., 1978b. Systematics and the Popperian paradigm. Syst. Zool., 27: 381-388.

Platt, J.R., 1964. Strong inference. Science, 146: 347-353.

Popper, K.R., 1968. The Logic of Scientific Discovery. Harper and Row, New York, N.Y., 480 pp.

Popper, K.R., 1970. Normal science and its dangers. In: I. Lakatos and A. Musgrave (Editors), Criticism and the Growth of Knowledge. Cambridge Univ. Press, Cambridge, pp.51-58.

Poundstone, W., 1985. The Recursive Universe. Monrow,
Contemporary Books, Chicago, Ill., 252 pp.

Read, C.B., 1937. The flora of the New Albany Shale. Part 2. The Calamopityeae and their relationships. U.S.G.S. Prof. Pap., 186E: 81-104.

Rogers, H,, 1967. Theory of Recursive Functions and Effective Computability. McGraw-Hill, New York, N.Y., $482 \mathrm{pp}$.

Rothwell, G.W., 1975. The Callistophytaceae (Pteridospermopsida): I. Vegetative structures. Palaeontographica, 151B: $171-196$.

Rothwell, G.W., 1982. New interpretations of the earliest conifers. Rev. Palaeobot. Palynol., 37: 7-28.

Rothwell, G.W., 1985. The role of comparative morphology and anatomy in interpreting the systematics of fossil gymnosperms. Bot. Rev., 51: 319-327.

Rothwell, G.W. and Warner, S., 1984. Cordaixylon dumusum n. sp. (Cordaitales). I. Vegetative structures. Bot. Gaz., 145: 275-291.

Salmon, W.C., 1967. The Foundations of Scientific Inference. Univ. Pittsburgh Press, Pittsburgh, Pa., $157 \mathrm{pp}$.

Schaeffer, B., Hecht, M.K. and Eldredge, N., 1972. Phylogeny and paleontology. Evol. Biol., 6: 31-46.

Schaffner, K.F., 1970. Outlines of a logic of comparative theory evaluation with special attention to pre- and postrelativistic electrodynamics. In: R. Stuewer (Editor), Logic of Comparative Theory Evaluation. Minn. Stud. Philos. Sci., 5: 311-373.

Schopf, J.M., 1978. Unstated requirements in nomenclature for plant fossils. Taxon, 27: 485-488.

Schweitzer, H.J. and Matten, L.C., 1982. Aneurophyton germanicum and Protopteridium thomsonii from the Middle Devonian of Germany. Palaeontographica, 184B: 65-106.

Scott, A.C., Galtier, J. and Clayton, G., 1984. Distribution of anatomically-preserved floras in the Lower Carboniferous in western Europe. Trans. R. Soc. Edinburgh, Earth Sci., 75: 311-340.

Shadle, G.L. and Stidd, B.M., 1975. The frond of Heterangium. Am. J. Bot., 62: 67-75.

Smoot, E.L., Jansen, R.K. and Taylor, T.N., 1981. A phylogenetic analysis of the land plants: a botanical commentary. Taxon, 30: 65-67.

Sober, E.R., 1975. Simplicity. Clarendon Press, Oxford, $189 \mathrm{pp}$.

Sober, E.R., 1983. Parsimony methods in systematics. In: N.I. Platnick and V.A. Funk (Editors), Advances in Cladistics, Vol. 2. Columbia Univ. Press, New York, N.Y., pp.37-47.

Sokal, R.R. and Sneath, P.H.A., 1963. Principles in Numerical Taxonomy. Freeman, San Francisco, Calif., 359 pp.

Stein, W.E., 1981. Reinvestigation of Arachnoxylon kopfii from the Middle Devonian of New York State, U.S.A. Palaeontographica, 177B: 90-117.

Stein, W.E., 1982. The Devonian plant Reimannia, with a discussion of the class Progymnospermopsida. Palaeontology, 25: 605-622.

Stein, W.E., Wight, D.C. and Beck, C.B., 1983. Arachnoxy- 
lon from the Middle Devonian of southwestern Virginia. Can. J. Bot., 61: 1283-1299.

Stein, W.E., Wight, D.C. and Beck, C.B., 1984. Possible alternatives for the origin of Sphenopsida. Syst. Bot., 9: 102-118.

Stewart, W.N., 1983. Paleobotany and the Evolution of Plants. Cambridge Univ. Press, Cambridge, $405 \mathrm{pp}$.

Stidd, B.M., 1981. The current status of medullosan seed ferns. Rev. Palaeobot. Palynol., 32: 63-101.

Stove, D., 1982. Popper and After. Pergamon Press, Elmsford, N.Y., $116 \mathrm{pp}$.

Suppe, F., 1977. The Structure of Scientific Theories. Univ. Illinois Press, Urbana, Ill., $818 \mathrm{pp}$.

Szalay, F.S., 1977. Ancestors, descendants, sister groups, and testing of phylogenetic hypotheses. Syst. Zool., 26: $12-18$.

Taylor, T.N., 1981. Paleobotany, an Introduction to Fossil Plant Biology. McGraw-Hill, New York, N.Y., 589 pp.

Taylor, T.N. and Millay, M.A., 1981. Morphologic variability of Pennsylvanian lyginopterid seed ferns. Rev. Palaeobot. Palynol., 32: 27-62.

Trivett, M.L. and Rothwell, G.W., 1985. Morphology, systematics, and paleoecology of Paleozoic fossil plants: Mesoxylon priapi, sp. nov. (Cordaitales). Syst. Bot., 10: 205-223.
Von Wright, G.H., 1957. The Logical Problem of Induction. Blackwell, Oxford, $249 \mathrm{pp}$.

Voss, E.G. et al., 1983. International Code of Botanical Nomenclature. Junk, The Hague, 472 pp.

Wagner, W.H., 1983. Reticulistics: the recognition of hybrids and their role in cladistics and classification. In: N.I. Platnick and V.A. Funk (Editors), Advances in Cladistics, Vol. 2. Columbia Univ. Press, New York, N.Y., pp.63-79.

Wanntorp, H.E., 1983. Reticulated cladograms and the identification of hybrid taxa. In: N.I. Platnick and V.A. Funk (Editors), Advances in Cladistics, Vol. 2. Columbia Univ. Press, New York, N.Y., pp.81-88.

Watrous, L.E. and Wheeler, Q.D., 1981. The out-group comparison method of character analysis. Syst. Zool., 30: 1-11.

Wiley, E.O., 1981. Phylogenetics. Wiley, New York, N.Y., $439 \mathrm{pp}$.

Wilson, E.O., 1965. A consistency test for phylogenies based on contemporaneous species. Syst. Zool., 14: 214-220.

Wing, S.L. and Hickey, L.J., 1984. The Platycarya perplex and the evolution of the Juglandaceae. Am. J. Bot., 71: $388-411$

Yasuhara, A., 1971. Recursive Function Theory and Logic. Academic Press, New York, N.Y., 338 pp. 